\title{
A Divided Discipline? Mapping Peace And Conflict Studies
}

Jonathan Bright, Oxford Internet Institute, University of Oxford

John Gledhill, Department of International Development, University of Oxford

For publication in International Studies Perspectives (Forthcoming, 2018)

\begin{abstract}
Scholars in the field of "peace and conflict studies" have long worried that their discipline is divided -- between studies of war and warmaking, and studies of peace and peacemaking. However, empirical research into the existence, extent, and nature of such a division is scarce. We remedy this, by addressing two questions: 1) How is work in the field of peace and conflict studies distributed between its two nominal pillars: "peace" and (violent) "conflict"? 2) To what extent is there communication and exchange between the two sets of studies? Making use of a unique combination of methods, we find that studies of violence hold a dominant position in the field, although there is also a sizable body of work that explores topics of peace, understood as conflict prevention and/or response. That said, we find limited evidence of intellectual exchange between studies of war/making and peace/making. We also find evidence of gendered, regional, and methodological divides. We argue that such schisms may be preventing scholars of peace and conflict from collectively realizing the founding ontological goal of their discipline, which was to understand the causes of war in order to contribute to an understanding of how conflict can be managed peacefully.
\end{abstract}

Keywords: Peace and conflict studies; security studies; peace research; biblometrics. 


\section{A Divided Discipline? MapPing Peace And Conflict Studies}

The study of "peace and conflict" is a core area of investigation in political science, international relations, and cognate disciplines. Around the world, there are hundreds of research institutes, academic departments, and professorial chairs in peace and conflict (IPRA n.d.). Each year, thousands of students pass through academic programs that focus on peace and conflict studies (Peace and Collaborative Development Network n.d.). Those students and their professors produce a vast body of research, which they present at conferences run by professional associations of peace and conflict scholars. Some of that research is later published in academic journals that specialize in the study of peace and conflict (see Human Dignity and Humiliation Studies n.d.). And, while the readership of those journals is typically restricted to an academic audience, the non-academic world is exposed to ideas generated by peace and conflict scholars (Paris 2011) when those ideas are filtered through government reports, journalistic accounts, and even a dedicated Wikipedia page.

While "peace and conflict" is a common moniker, however, there has long been suspicion that studies of peace and conflict do not constitute a coherent, interconnected body of research. Rather, for some, the field of peace and conflict studies is divided between treatments of war and violent conflict, on one side, and studies of peace and conflict management, on the other. Others reject the idea of such a division, arguing that the concepts of war and peace are mirror images of one another, and so it is impossible to study one topic without engaging the other. While there is a logic to both claims, these contrasting understandings are, at present, assertions rather empirical observations, since there have been few systematic investigations of the field of peace and conflict studies. In this article, we partly remedy that empirical void by mapping the output of peace and conflict scholars in political science journals over the past 20 years, with a view to establishing whether works published in those journals constitute a coherent and interconnected body of research -- or a divided discipline.

The question of community coherence is vital for peace and conflict studies because it speaks to whether scholars in the field are realizing the founding ontological goal of their discipline, which was to use the study violent conflict as a basis for understanding how such conflict can be managed, and its effects mitigated (see Wallensteen 2001, 3). In this article, we assume that it is only possible for scholars to realize that goal by collectively studying war and violence and efforts to prevent, manage, and respond to violence. We also assume that there 
should be dialogue and engagement between these two areas of study. Since it is currently unclear whether these assumptions reflect reality, however, we address two empirical questions. First, how is work in the field distributed between its two nominal pillars; studies of peace and peacemaking, on one hand, and studies of violent conflict and war making, on the other? Second, is there communication and exchange between studies of peace and studies of violent conflict, and, if so, which areas of investigation are most active in promoting such an exchange? To answer these questions, we analyze the content of peace and conflict articles that have appeared in 18 leading journals of political science and international relations over the past 20 years, making use of a unique combination of methods including survey data, manual content coding, machine learning, and network analysis.

In response to the descriptive query, we find that the study of peace and conflict is dominated by treatments of war and violence; such studies constitute a majority of published works in our sample; they receive the largest number of citations; and they are particularly likely to be published in top-ranked journals. Despite this apparent "violence bias," however, we also find reason to reject the notion that peace research is just the study of war (see Gleditsch et al. 2014). Instead, there is also a recognizable body of work that addresses peace-related processes and outcomes, such as conflict prevention, peacemaking, and peacekeeping.

On the analytic question of intellectual exchange, we find only limited evidence of cross-citation between studies of conflict and studies of peace. We also find that articles focusing on violent conflict have a particularly strong tendency to cite other articles that explore violence, rather than engage with articles that address the more "pacific" topics of conflict prevention or response. While we conclude that the study of peace and conflict within political science is largely schismatic, we recognize that there is some degree of communication across the peace/conflict divide. To that end, we identify particular topics that encourage scholars to bridge the divide.

In the sections that follow, we first present a genealogy of peace and conflict studies, highlighting claims that the field has long been divided. We then detail our data sources and sketch our methods. In the two following sections, we present the results of each of our two empirical investigations, in turn. Given our finding that the discipline is broadly divided, we then offer a set of tentative explanations of that division. In so doing, we identify institutional, gendered, and regional cleavages within the field. We conclude by proposing a number of ways in which divisions might be broken down, so that studies of violent conflict can better contribute to the study and practice of peaceful conflict management, and, conversely, so that the study and practice of peace can be built on a solid understanding of conflict dynamics. 


\section{Peace and Conflict Studies: Genealogy of a Divided Discipline}

Peace and conflict studies developed as a distinct area of study in response to the devastation of the Second World War. Driven by a conviction that such destruction must never be repeated, a diverse set of scholars came together with the goal of developing academic research that could contribute to shaping a world in which conflict is managed without resort to violence. In that way, the study of peace and conflict was, from the outset, underwritten by a clear normative goal (see Rapoport 1975, 43). That said, while there was broad consensus on the merits of that goal, disagreement soon developed over how norms should inform the way that peace and conflict scholars do their work (Buzan and Hansen 2009, 134; Kelman 1981, 102-3).

One set of peace and conflict scholars saw that a principled aversion to violence could -- and should -- inform what scholars study, but not how they study it. That is, they saw that antipathy to war should direct researchers toward the study of violent conflict and its resolution but, beyond that point, data and evidence should replace norms as a guide for research (see Boulding 1978, 127). This position was shared, in particular, by a set of US-based researchers including Kenneth Boulding, J. David Singer, and Anatol Rapoport -- many of whom transferred into the study of peace and conflict from disciplines such as mathematics, physics, psychology, and economics (Kelman 2012, 364-65). With backgrounds in quantitative sciences, these scholars were broadly committed to what the editors of the Journal of Conflict Resolution would later call "hard-nosed peace research" (Russett and Kramer 1973, 4). That is, they were committed to the collection and analysis of quantitative data on the causes of collective violence and war (see Wallensteen 2002, ch.2). The early empiricists had a clear epistemological reason for this substantive focus; they believed that it was only by developing a scientific understanding of violent conflict that it would be possible to change perceptions about the nature of war and, ultimately, bring about institutional reforms that would facilitate the peaceful management of conflict (Deutsch 1970, 473; Rapoport 1975, 49).

A second group of scholars, many of whom were based in Europe, agreed with their empiricist colleagues that peace research should contribute to the construction of peaceful societies. However, they were not willing to set this normative assumption to the side once it had informed their decision to study peace and conflict. Rather, they saw that normative considerations should also shape the way in which peace research is conducted and disseminated. Given this belief, these scholars rejected the idea that peace and conflict studies should be restricted to analyses of the causes of physical violence. Instead, they argued that 
scholars should also aim to identify and expose socio-political structures that cause suffering and prevent individuals from realizing their full potential (Galtung 1969; 1985). Moreover, they argued that peace research should not be restricted to empirical studies. Rather, the likes of Johan Galtung and his followers claimed that peace researchers have a responsibility to: advocate for the realization of "peace by peaceful means" (Galtung 1996); educate students about the merits of such a normative position (see discussions in Vasquez 1976; Lopez 1985); and propose institutional changes that might transform, rather than simply manage, conflicts. These normative positions meant that so-called "humanist" scholars (Clemens 2012, 769) placed less emphasis on the scientific collection and analysis of large-n data than their empiricist colleagues. While that stance was grounded in epistemological and ontological assumptions, such data would have been difficult to collect in any case because many of the ideals propagated by humanists had not yet been put into practice (see Galtung 1964) and, as such, there was little relevant data to gather.

Throughout the 1960s, '70s, and ' $80 \mathrm{~s}$, the distance between empiricist and more normative approaches to the study of peace and conflict fluctuated. On occasion, some scholars seemed keen to bridge the divide by wedding a commitment to the promotion of social justice with an empirical focus on understanding the causes of war (see discussion of the Hamburg Project in Wallensteen 2002, 20-23). On other occasions, however, the divide between empiricists and humanists seemed chasmic, with surveys in the early and mid-1970s suggesting that the discipline had effectively become split between "two cultures" (Vasquez 1976).

The end of the Cold War promised to change the practice of peace and conflict and, thus, the study thereof. The dissolution of empires, states, and super-power support for unstable governments triggered a (temporary) spike in the frequency of civil wars in the late 1980s and early 1990s (Fearon and Laitin 2003, 77). At the same time, the end of super-power rivalry meant that permanent members of the United Nations Security Council were willing to work together to approve multilateral interventions aimed at minimizing the level of human suffering from civil wars in the short term, and building peace over the long term (Berdal 2010). As these interventions played out, some peace and conflict scholars became interested in studying the nature and efficacy of humanitarian missions, the mediation of internal conflicts, and postconflict reconstruction (Wallensteen 2011, 26-29).

This new substantive focus opened up scope for empiricists and normative scholars to respond to critiques they had previously levelled at one another. For empiricists, specifically, the opportunity to observe and investigate peace-focused outcomes such as humanitarian intervention and peacekeeping meant that these scholars could -- in theory -- then attend to the 
long-standing claim that their version of peace research was effectively violence research (see Johansen 2006). And for humanist scholars, the possibility of exploring institutionalized responses to violent conflict meant that they could test the validity of their theoretical and normative claims and, thus, speak to the criticism that their version of peace and conflict studies amounted to untested utopianism (see Walt 1991, 224).

Despite the possibility for reconciliation between factions, however, it is unclear whether intellectual bridges have actually been built over the past twenty years. That is, it remains unclear whether peace and conflict studies has evolved into a coherent field of study. At present, we have only partial answers to this question. Some of those answers have come from Gleditsch and his colleagues, in their analysis of works published in the Journal of Peace Research and the Journal of Conflict Resolution (Gleditsch et al. 2014). Asking whether peace research is "just the study of war?" Gleditsch et al. (2014) find that studies of violence and war, rather than peace, feature particularly prominently in those publications. This is certainly revealing, but the authors do not make broader claims about the field, since their analysis is restricted to just two journals. Furthermore, they have little to say on the topic of coherence within the discipline because they focus exclusively on the volume of content published on various topics, without investigating connections between those topics. That question has been tackled, in part, by Sillanpää and Koivula (2010), who have examined citation networks within the field. After identifying four distinct clusters of research within peace and conflict studies, the authors argue that studies of civil war have few connections to studies of a topic they call "prerequisites for peace" (Sillanpää and Koivula 2010). This suggestion of division is an important insight but, again, it can only be considered a snapshot of the field because their findings are based on an investigation of the citation patterns of just 112 articles.

Recognizing that the above-mentioned studies give us good starting points to address the question of community coherence within peace and conflict studies, we build on them in the sections that follow. Following a discussion of data and methods, we first expand on the work of Gleditsch et al. (2014) by asking how work on peace and conflict is distributed between its two nominal pillars; studies of peace and peacemaking, and studies of violent conflict and war making. We then expand on the work of Sillanpää and Koivula (2010) by examining whether there is there communication and exchange between studies of peace and studies of violent conflict, and, if so, which areas of the discipline promote such an exchange. 


\section{Methodology}

While we recognize that peace and conflict is studied from many different disciplinary perspectives (political science, sociology, law, theology etc.), our analysis is restricted to an investigation of peace and conflict studies within political science and international relations - partly because these are our own disciplines, and partly because this is where much of the relevant literature has been published. There is also methodological logic in restricting our analysis to a single disciplinary domain; after all, if there is evidence of community coherence within peace and conflict studies, then such coherence will be most visible among scholars who investigate peace and conflict from the same disciplinary perspective; by contrast, if there is evidence of division even among scholars who come from the same disciplinary background, then it will be safe to assume that deeper divides exist across peace and conflict studies, more generally.

\section{Data Sources}

To answer our questions, we follow other works that have studied patterns of scientific study and collaboration in political science and international relations (e.g. Kristensen 2012) by making use of published journal articles as our core source of data. While we recognize that academic fields manifest themselves in many ways beyond publications (for example, in conferences), scholarly works that appear in journals generally represent the most important output of academic disciplines and, thus, a study of that output in peace and conflict studies is arguably the best way of assessing the field, and the extent to which it is divided.

The sample of articles that we use throughout the study is drawn from two sets of political science journals: nine specialist publications of peace and conflict studies, and nine generalist journals of international relations. To identify which specialist journals to investigate, we surveyed scholars who work with leading peace and conflict institutions around the world. When running our survey, we ensured that potential respondents were based in institutions of "war studies," "peace studies," and "peace and conflict studies" in roughly even numbers, in order to draw on the views of scholars with varying epistemological and methodological perspectives. Those who agreed to participate were asked to self-identify as scholars of: 1) the causes and dynamics of conflict, violence, and/or war; 2) responses to conflict and/or post-conflict reconstruction; and 3) both of the above, in equal measure. Respondents were then asked to nominate the most influential journals in their area(s) of study, and we used those responses as a basis for choosing journals to sample. We included the three 
publications that were top-ranked by scholars who self-identified as working on violent conflict and responses "in equal measure," as well as three journals that were uniquely identified by scholars who self-identified as working on violent conflict, and conflict responses, respectively. ${ }^{1}$ Together, these criteria saw us draw articles from: Cooperation and Conflict, International Peacekeeping, International Security, Journal of Conflict Resolution, Journal of Peace Research, Journal of Strategic Studies, Security Dialogue, Security Studies, and Terrorism and Political Violence.

To select generalist journals to sample, we relied on a ranking of the most influential journals in the wider field of international relations, as identified by scholars who participated in the renowned TRIP survey (Maliniak et al. 2012, 52). We set specialist peace and conflict journals to the side, since we had already included them through the process described above. We also excluded publications that do not appear in the SCOPUS database of academic abstracts and citations, since it was to be our primary source of bibliographic and citation data, as detailed below. ${ }^{2}$ Applying these criteria, we identified nine further publications for investigation: European Journal of International Relations, Foreign Affairs, Global Governance, International Affairs, International Organization, International Relations, International Studies Quarterly, Millennium, and World Politics.

The content of articles that have appeared in these 18 journals over the past two decades provided our primary data for assessing the post-Cold War state of the field. Although we recognize that there are, clearly, other outlets for work in peace and conflict studies, we believe that articles published in these journals provide a broadly representative sample of the most influential studies of peace and conflict that have been produced by political scientists, where "influence" is understood in terms of academic diffusion and citation. For each journal, we extracted information on articles published in the period 1996-2015 from SCOPUS, although it should be noted that, while SCOPUS offers good data for all journals of interest during this time period, that data does not cover all years, for all journals. In the online Appendix, we provide details of which years were available. Our results are weighted to address these gaps in coverage.

\footnotetext{
${ }^{1}$ Further details of the survey, survey results, and journal selection method are provided in the Appendix.

${ }^{2}$ SCOPUS is a subscription-based propriety database run by Elsevier: https://www.scopus.com/
} 


\section{Concepts and Coding}

Given our interest in identifying whether there is a divide between the two nominal pillars in the field -- "peace" and "conflict" -- our first step was to operationalize these terms in a way that would allow us to categorize articles under those headings, while ensuring validity, reliability, and replicability. This proved challenging because both peace and (violent) conflict are disputed terms (see Galtung 1969). Moreover, while some scholars see that peace and conflict are polar opposites, others have argued that the conceptual and practical lines between peace and war are blurred (Keen 2000; MacGinty 2010). Given these challenges, we decided to classify articles according to the observable processes and/or outcomes under investigation, rather than using any more subjective, normative, or interpretivist criteria. When taking this empiricist approach, we distinguished between articles in which the primary observable processes or outcomes related to: 1) "conflict," understood as war, terrorism, and other forms of violence; 2) "peace," understood as direct and structural conflict prevention, efforts to respond to violent conflict in the form of mediation or peacebuilding, and responses to human insecurity; ${ }^{3} 3$ ) both of the above in a single study ("mixed"); and 4) none of the above ("unclassifiable"). Our full codebook is provided in the Appendix.

Since assigning articles to these categories required a degree of expert insight, we organized the coding effort as a two-step process, in which manual coding laid the foundation for the development of an automatic classifier (see Grimmer and Stewart 2013). To that end, two researchers first independently read the main text of 50 randomly-selected articles from each of our 18 journals, and they placed those 900 studies into one of the substantive categories described above. ${ }^{4}$ Where the coders disagreed in their classification of the main substance of articles (around 25 percent of the time), ${ }^{5}$ we followed the practice adopted by the TRIP survey $(2013,19)$, by independently triple-coding the substance of articles, before deciding on a final code. We also manually recorded any biographical data on authors that was published alongside their studies (gender, affiliation etc.), and we noted their methods.

As a second step, we built an automatic article classifier, which assigned a code of either "peace," "conflict," or "unclassifiable" to all articles contained within the SCOPUS database that had been published in our journals of interest (just over 7,000 articles). The

\footnotetext{
${ }^{3}$ In our initial coding, we distinguished between articles that focus on conflict prevention and articles on conflict response. For our analysis, we combined these two categories into the single category of "Peace."

${ }^{4}$ We chose a stratified sampling method because different journals publish different volumes of content, and we wanted to have enough data from journals that publish fewer studies. This stratification is taken into account in all of the results presented below.

${ }^{5}$ Full details on intercoder reliability (ICR) scores are provided in the Appendix.
} 
automatic classifier worked by examining the titles and abstracts of articles that we had manually coded. By looking for words that were common within articles classified as "peace," but uncommon within articles coded as "conflict" (and vice versa), the classifier was trained to recognize linguistic differences between the categories. Note that we did not automatically classify "mixed" articles because the language within them was (unsurprisingly) too difficult to separate out as a distinct category, and we recognize this as a limitation.

After building the classifier, we assessed its accuracy, finding that it agreed with our manual coding around 80 percent of the time. The most evident source of error was that some "peace" articles were mistakenly coded as "unclassifiable." Consequently, we would expect the relative number of "peace" articles to be lower in our automatic sample than in our manual sample. Further information on the automatic coding process, diagnostics, and coding accuracy are provided in the Appendix.

\section{Network Analysis}

Data gathered through manual and automatic coding gave us immediate answers to our first question: "What do scholars of peace and conflict study?" In order to address our second question ("Is there communication and exchange between studies of peace and studies of violent conflict, and, if so, which areas of the discipline promote such an exchange?"), we chose to employ citation network analysis, which is a method widely used to study the internal dynamics of academic disciplines (for example, Chen 1999; Lehmann et al. 2003; Shibata et al. 2008). Following this practice, we designated each of the articles in our dataset as a "node," and each of the citations within those articles as "links" between nodes within our overall network. When one article in our sample cited another, a directed link was formed -- from the article doing the citing, to the article being cited. Since we would expect works from strongly connected areas of study to frequently cite each other, and the reverse to be true for research areas that are only loosely connected, the observed citation networks allowed us to build a picture of community structures within the field.

We drew the raw citation data for our network analysis from SCOPUS. However, since SCOPUS does not provide citation information in a way that easily allows for cross-citation study, we needed to generate a way of automatically detecting citations between articles in our sample. To do so, we used a computer script that searched the list of references of each article in our dataset, identifying titles that appeared in the lists of references of all other articles in the dataset. Further details of this automatic citation matching method, as well as the techniques 
we used to validate it, are provided in the Appendix. In sum, we found that the script offered a good degree of accuracy; while it tended to slightly understate the true numbers of citations, it did not do so in a way that would have biased our results.

\section{Results I: Distribution of Work in Peace and Conflict Studies}

In this section, we address our first research question, which concerns the distribution of work between studies of peace and studies of conflict. To do so, we present descriptive statistics based on our manual and automatic coding. In total, 417 of the 900 (46 percent) articles that we manually coded fell into one of our major categories of "peace," "conflict," or "mixed" studies, while the remainder were placed in the "unclassifiable" category. This high volume of unclassifiable articles is not a surprise, as our sample included articles from many generalist international relations journals. The automatic coding of 7124 articles, meanwhile, produced 2381 articles (33 percent) that could be coded as either "peace" or "conflict." The figure and summary statistics below are based exclusively on the subset of articles that could be classified. We would highlight that, since our manually coded sample was selected in a stratified manner, our results are weighted to take account of this stratification.

Our first finding is that studies of violent "conflict" constitute the bulk of political science publications that address themes of peace and conflict. This is visualized in Figure 1, and detailed in the summary statistics presented in Table 1. As evident there, studies of "conflict" constitute a majority of classifiable articles (71 percent of the automatic sample, and 53 percent of the manual sample), which gives credence to Wallensteen's intuition that "peace research is concerned with the question of violence" $(2011,15)$. That said, our results also show that peace and conflict scholars are not only concerned with violent conflict. Rather, there is a substantial body of work that investigates the prevention of violent conflict and/or responses to such conflict. Indeed, 29 percent of our automatically-coded articles and 35 percent of our manually-classifiable articles fell into the "peace" category. While we consider the manual figures to be a more accurate reflection of the field due to recognized limitations of the automatic coding process, the overall similarity between the two sets of results enhances our confidence in the automatic coding. Finally, we note that only a limited number (12 percent) of our manually-coded sample fell into the "mixed" category, which suggests that few individual articles can make a valid claim to focus on both peace and conflict. This category, as indicated above, is not included in the automatic coding. 
Figure 1: Distribution of articles by content
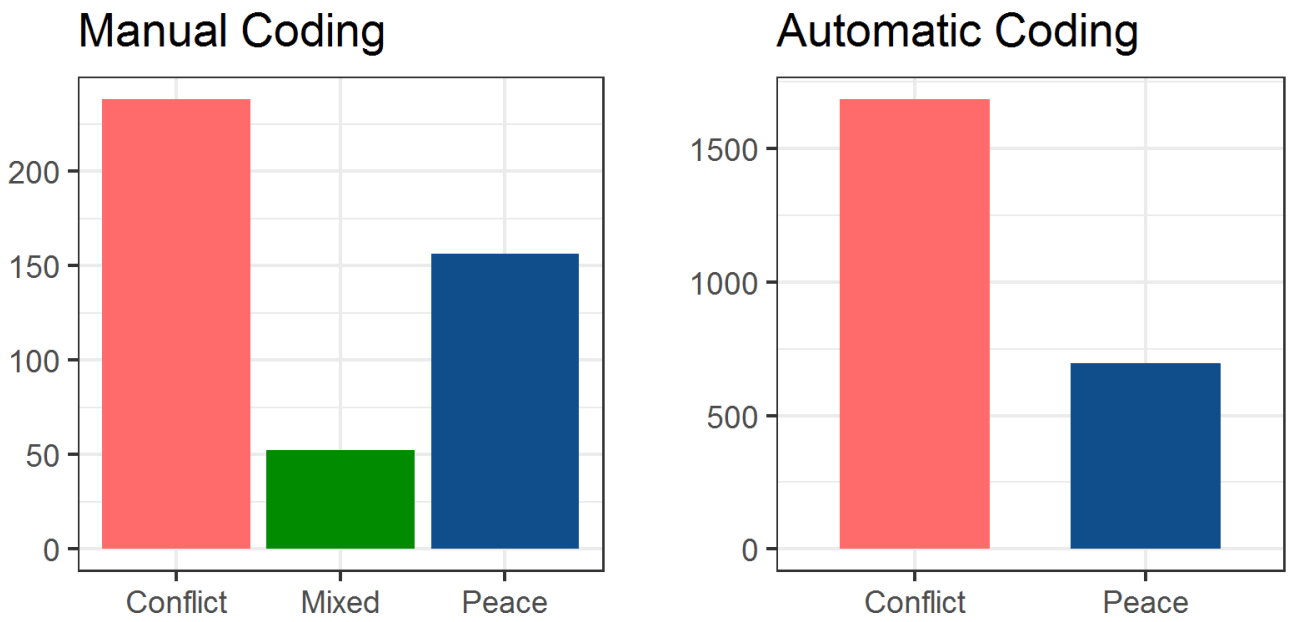

Our second finding is that studies of "conflict," on average, carry much greater impact within the field than do studies of "peace." This conclusion is based on two measurements. First, we looked at the average number of citations that articles in each category receive per year (the annual figure is important because, of course, older articles are likely to have been cited more often). As can be seen in Table 1, studies of "conflict" receive, on average, considerably more citations (1.8 per year in the automatic sample, 1.9 per year in the manual sample) than do articles coded as "peace" (1.3 and 1.1, respectively).

Table 1: Distribution of content, and citation analysis

\begin{tabular}{|l|c|c|c|c|c|c|}
\hline & \multicolumn{4}{|l|}{ Manual Coding } & \multicolumn{2}{l|}{ Automatic Coding } \\
\hline & $\begin{array}{l}\text { Frequency } \\
\text { in Sample }\end{array}$ & $\begin{array}{l}\text { \% of } \\
\text { Classifiable } \\
\text { Articles }\end{array}$ & $\begin{array}{l}\text { Average } \\
\text { Citations } \\
\text { per Year }\end{array}$ & $\begin{array}{l}\text { Frequency } \\
\text { in Sample }\end{array}$ & $\begin{array}{l}\text { Average } \\
\text { Classifiable } \\
\text { Articles }\end{array}$ & $\begin{array}{l}\text { Citations per } \\
\text { Year }\end{array}$ \\
\hline Conflict & 220 & $53 \%$ & 1.9 & 1685 & $71 \%$ & 1.8 \\
\hline Peace & 148 & $35 \%$ & 1.1 & 696 & $29 \%$ & 1.3 \\
\hline Mixed & 49 & $12 \%$ & 1.6 & N/A & N/A & N/A \\
\hline Total & 417 & $100 \%$ & 1.6 & 2381 & $100 \%$ & 1.6 \\
\hline
\end{tabular}

As a second measure of impact, we looked at whether there is a correlation between the recognized impact factor of the journals we sampled and the content of articles published in those journals. Figure 2, below, presents the results of that investigation. The Y-axis plots 
journals' impact factors, as reported in the 2014 Journal Citation Report, ${ }^{6}$ and the X-axis plots the "peace-conflict orientation" of journals, which is an indicator of the relative number of "peace" and "conflict" articles that each journal publishes. To derive that orientation, we applied the following formula to each journal we sampled:

$$
\frac{\text { Number of Conflict Articles }- \text { Number of Peace Articles }}{\text { Number of Conflict Articles }+ \text { Number of Peace Articles }}
$$

An orientation of -1 would indicate that all classifiable articles from a given journal were manually coded as "peace," an orientation of 1 would suggest that all classifiable articles were manually coded as "conflict," and an orientation of 0 would indicate that an equal number of classifiable articles from a given journal were placed into each category. To facilitate visualization in Figure 2, we color-coded each journal to reflect its orientation; the color scale runs from pure blue (for complete "peace" orientation), through purple (for "mixed" orientation), and onto pure red (for complete "conflict" orientation).

The figure suggests a broad correlation between the content of the journals we investigated and the impact factors of those journals. While we recognize that the correlation would not be considered statistically significant, ${ }^{7}$ it is clear that the journals with the highest impact factor scores (International Security, Journal of Peace Research, International Organization, World Politics) all focus on processes and outcomes of violent "conflict" (when publishing in the area of peace and conflict studies). Beyond that clear observation, the pattern is a little mixed. That said, it is notable that journals with the strongest "peace" orientations all have impact factor scores that fall toward the lower end of the scale. And, most notably, the only journal that is almost exclusively dedicated to the study of "peace"-related topics (International Peacekeeping) carries the lowest impact factor of any publication that we sampled.

\footnotetext{
${ }^{6}$ Available from: https://jcr.incites.thomsonreuters.com

${ }^{7}$ A Pearson correlation test gives a correlation coefficient of 0.4 and a $\mathrm{p}$ value of 0.09 . Of course, the sampling method was deliberately non-random, so such a test is not strictly valid.
} 
Figure 2: Journals, orientation, and impact factor

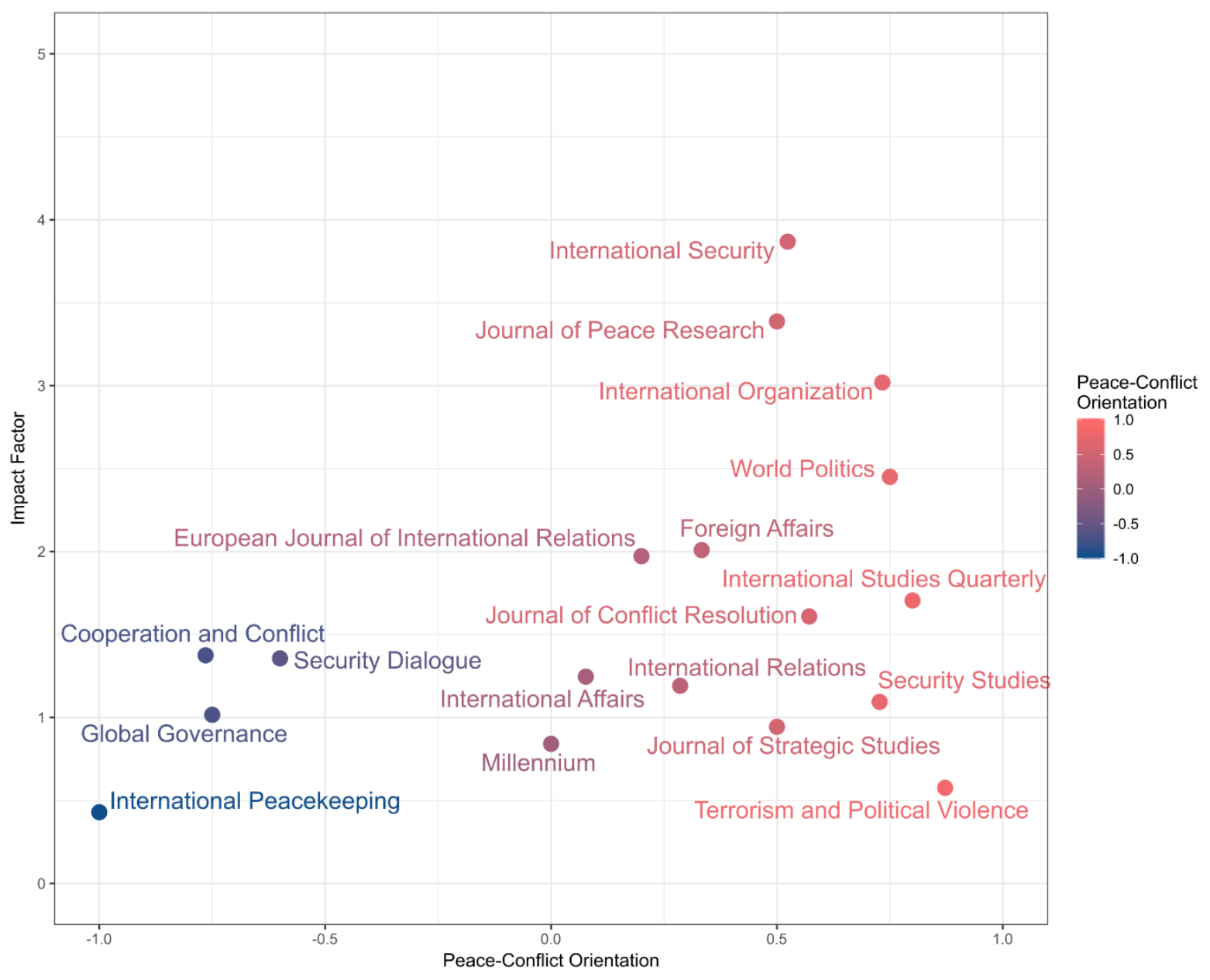

In sum, then, our descriptive statistics point to two broad conclusions. First, treatments of violent "conflict" (i.e. war, terrorism, and other forms of violence) have a dominant position in peace and conflict studies -- partly in terms of the volume of publishing but especially in terms of the attention that these publications receive, measured by citations. In that way, the field of peace and conflict studies might be thought of as having something of a violence bias. That said, we also conclude that there is a reasonable number of studies on topics of "peace," including studies of conflict prevention, peacemaking, peacekeeping, and human securitization. Thus, overall, scholars of peace and conflict studies seem do just that -- they study both peace and (violent) conflict, albeit in a way that is skewed toward the latter.

\section{Results II: Connections between Studies of "Peace" and Studies of "Conflict"}

In this section, we address our second question, which concerns connections between studies of "conflict," on one hand, and studies of "peace," on the other. Our investigation is divided into two parts. First, we examine whether studies of "peace" and studies of "conflict" 
engage with each other through cross-citation (creating community coherence), or whether articles from a given category only tend to cite other articles from that same category (creating disciplinary division). ${ }^{8}$ Second, to the extent that there is evidence of exchange between studies coded as "peace" and "conflict," respectively, we investigate whether particular types of studies or topics facilitate such cross-community exchange.

\section{A Coherent Community or Divided Discipline?}

To assess the degree of exchange between studies of "peace" and "conflict," we observed patterns of citations in the two categories, measuring both the number of internal citations (that is, citations going from a "peace" article to another "peace" article, or a "conflict" article to another "conflict" article) and external citations (that is, citations going from a "peace" article to a "conflict" article, or vice versa). We also compared the observed number of external citations of each category with the number of external citations that would have been expected, if citing took place purely at random across all articles in our full sample. This expected number was simply the percentage of articles found in the opposite category (hence, for example, we would expect 71 percent of the "peace" citations to go to "conflict" because the "conflict" articles constitute 71 percent of all classifiable articles). By summing the numbers of expected external citations for each category, we also produced an expected number of external citations for the network as a whole, if citations were distributed at random across the full sample. Including these expected citation counts in our analysis allowed us to compare the observed patterns of external citations with a kind of null hypothesis, defined as the pattern of citing that we would see if there were no division between studies of "peace" and studies of "conflict."

The results of all calculations are reported in Table 2 . Since the number of citations in our manually coded sample was low, we have only presented data from our automaticallycoded sample. The table suggests that peace and conflict studies is broadly divided. This can first be inferred from the left-most column, which aggregates data from all classified articles and, as such, gives us snapshot of the internal dynamics of the field of peace and conflict studies as a whole. These results suggest that, if there were no divisions within the field, we would expect 37 percent of citations in our sample to be external (i.e. to link across categories) -either from studies of "peace" to studies of "conflict," or vice versa. In actuality, however, only

\footnotetext{
${ }^{8}$ Note that, for this phase of the analysis, we were forced to exclude the journal Foreign Affairs, simply because there is very limited information available on its citations, which meant that they proved impossible to track.
} 
17 percent of citations cross categories. Thus, we observe less than half the cross-category linking that we would see if there were no divisions in the field.

Table 2. Observed and expected citation patterns for automatically-coded articles

\begin{tabular}{|l|l|l|l|}
\hline Category & $\begin{array}{l}\text { All Classified } \\
\text { Articles (i.e. Peace } \\
\text { + Conflict) }\end{array}$ & Peace & Conflict \\
\hline Number of Articles in Sample & 2381 & 696 & 1685 \\
\hline Observed Citations & 4834 & 897 & 3937 \\
\hline Observed Internal Citations & 4012 & 478 & 3534 \\
\hline Observed External Citations & 822 & 419 & 403 \\
\hline Observed External Citations (\%) & $17 \%$ & $47 \%$ & $10 \%$ \\
\hline Expected External Citations (\%) & $37 \%$ & $71 \%$ & $29 \%$ \\
\hline Actual : Expected (Ratio) & 0.46 & 0.66 & 0.35 \\
\hline
\end{tabular}

The idea of division is reinforced when we disaggregate the results and look at the citation patterns for each of the two discrete categories. This step reveals that the "conflict" category, in particular, is highly insular; only 10 percent of the citations in "conflict" articles refer to articles that are classified as "peace." This is approximately one third of the figure we would expect to see if citations were distributed randomly across our whole sample (29 percent). Studies in the "peace" category, by contrast, are somewhat less insular; 47 percent of citations from such articles reach across the divide and refer to studies of "conflict." This figure, however, is still only around two thirds the level of cross-citation that we would see (71 percent), if citations were distributed randomly between articles in the two categories. Still, in general, it appears that studies classified in the "peace" category do a better job of reaching across the peace/conflict divide than do studies of "conflict." 


\section{Connections between "Peace" and "Conflict"}

Since the assumed goal of peace and conflict studies is to link knowledge of violent conflict to the study and practice of peaceful conflict management, the findings presented above suggest that scholars may not be collectively realizing that goal. That said, our findings also suggest that some citation takes place across the peace/conflict divide, which points to the potential for meaningful cross-community exchange. Given that potential, it is important to know whether particular topics facilitate such exchange. To identify such topics, we used an automatic community detection algorithm to establish whether there are particular areas of investigation that do a good job of connecting studies of "peace" with studies of "conflict," and vice versa.

Community detection provides a kind of bottom-up method for studying connections and divisions within networks. In simple terms, these algorithms typically function by first observing the structure of citation links within a given network, and then dividing the network into clusters of articles that have a relatively high number of internal links (i.e. they cite one another a lot), but a relatively low number of external links. While there is a wide variety of community detection algorithms available (Fortunato 2010), we used the Infomap approach because it is specifically designed to study communities on the basis of patterns of information flow, and it was developed for use on academic citation networks (Rosvall and Bergstrom 2008).

In addition to identifying clusters of articles through Infomap, we also developed a means of automatically labelling them. To do so, we calculated "tf-idf" scores for all the words in the titles of the articles in each cluster. These scores are calculated by computing the ratio of the "term frequency" ("tf," i.e. the number of times a given word appears within the titles of articles in discrete clusters) to the "inverse document frequency" ("idf," i.e. the number of times the word appears within the titles of the whole corpus of articles in our sample). Words that appeared frequently within a given cluster, but infrequently outside of it received high values, and we assumed these words are indicative of the thematic focus of the clusters in question. We then used the five top scoring words for each cluster as a basis for assigning a readable label to the communities we detected. ${ }^{9}$ Full details of the community detection and labelling processes are provided in the Appendix.

\footnotetext{
${ }^{9}$ Since we evidently did not know the labels of any of the clusters in advance, we lack a good way of truly assessing the accuracy of this measure. However, the cluster names have good face validity.
} 
Our results are visualized in Figure 3. Each node represents a cluster of articles that closely cite one another. To simplify the picture, we chose to visualize only a subset of clusters. Specifically, we chose to show the 10 clusters with the most "conflict" articles within them and the 10 clusters with the most "peace" articles. One cluster scored highly in terms of both "peace" and "conflict" articles, so this cluster was added as well, leading to a total of 21 clusters being visualized. The size of each node reflects the number of articles in the cluster, and the color reflects its "peace-conflict orientation." Here, this orientation reflects the relative number of "peace" and "conflict" articles that are in each cluster; where most articles were automatically coded as "conflict," the node is red; where most were coded as "peace," the node is blue; and where a cluster includes some articles that were coded as "conflict" and some that were coded as "peace," the node is a degree of purple. Thus, for example, the red node in the center of the figure, labeled "civil war and rebellion," represents a large cluster of interconnected articles that were mainly coded "conflict"; the blue node toward the bottom left, labeled "responsibility to protect," is a smaller cluster of connected articles, most of which were coded "peace"; and the purple node near the center, labelled "democratic peace," is a moderate-sized cluster of connected articles, some of which were coded as "conflict" and others as "peace." The exact number of articles in each cluster and their distribution between the "peace" and "conflict" categories are specified in the Appendix.

Each node is positioned automatically using the Fruchterman-Reingold layout algorithm (Fruchterman and Reingold 1991). This algorithm is based on the citation links between clusters; where articles from one cluster cite articles in another cluster, the respective nodes are positioned near one other, and where there are few or no citations across pairs of clusters, they are distant. The arrows between nodes indicate citations going from one cluster to another, with darker arrows indicating more citations and, thus, a closer connection between clusters.

Overall, the figure reinforces the idea that peace and conflict studies is a divided discipline. This is evidenced in the fact that red ("conflict") nodes are all located near one another in the upper section of the graphic, while blue ("peace") nodes are located together at the bottom of the figure. Such an arrangement suggests that studies of "conflict"-focused topics cite one another to a high degree, and the same is broadly true for "peace" topics, but there is only limited citation between clusters that fall on either side of the peace/conflict divide. Despite this overall trend, however, close inspection of the figure and the data underlying the 
figure $^{10}$ suggests that division is not complete. Rather, it seems that certain topics facilitate a degree of communication and exchange within the discipline. Such exchange can be seen to take place in two ways -- within clusters of articles that focus on a given topic, and across clusters of articles that focus on different topics.

Figure 3. Detected communities and citation networks

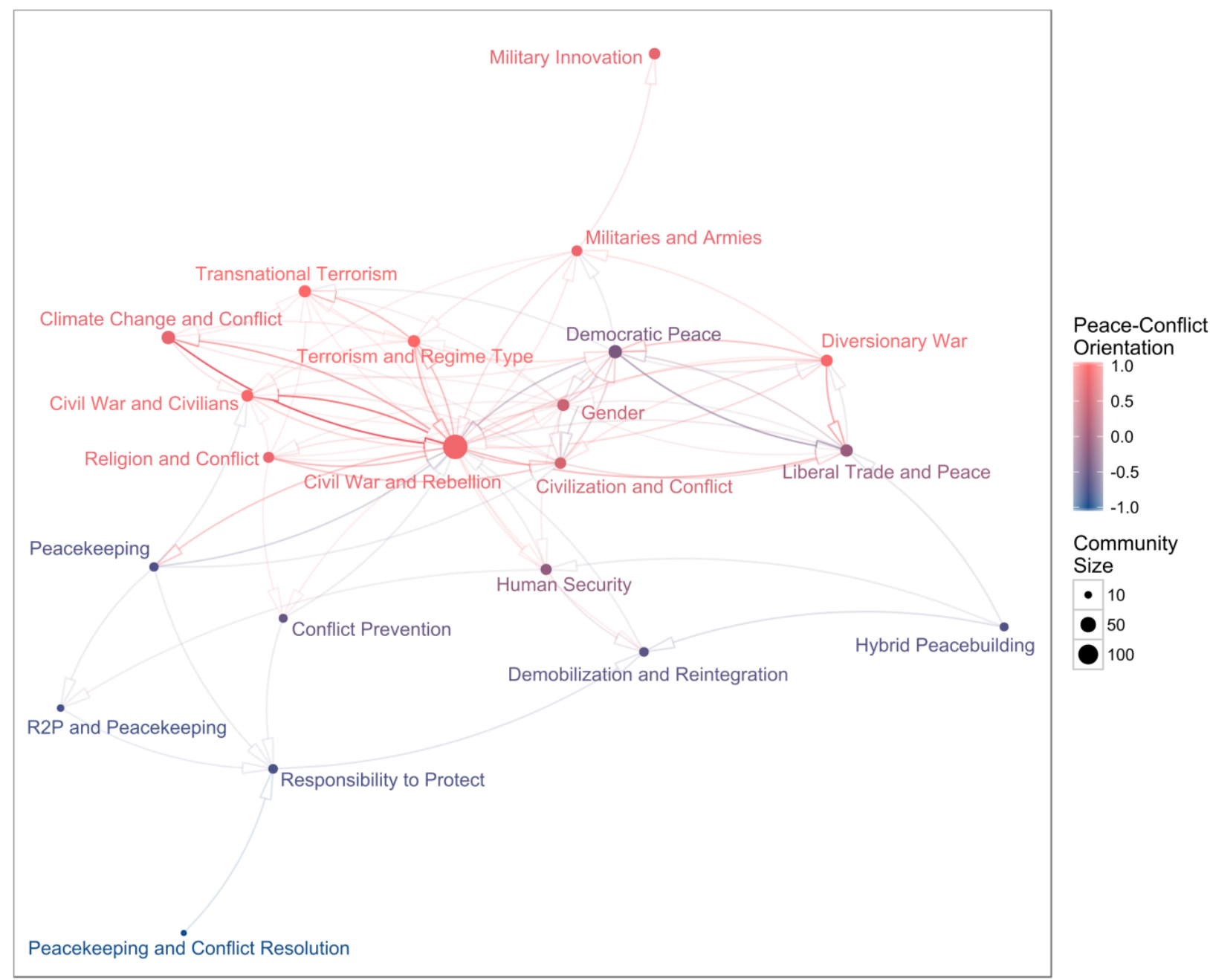

Within-cluster exchange takes place when scholars approach the study of a particular topic from contrasting perspectives -- either "peace" or "conflict" -- and then cite one another's varying approaches to that topic. In Figure 3, this dynamic can be seen to play out where scholars study topics associated with the purple-colored nodes, since these represent clusters of articles that share a common thematic focus, but some of the articles on those topics are coded as "peace," while others are coded as "conflict." When those variously-coded articles

${ }^{10}$ This data is available with the online replication materials. See the Appendix for details. 
cite one another's work on the topics in question, some of that within-cluster citing necessarily links studies of "peace" to studies of "conflict," and vice versa. Figure 3 suggests that this is the case for the nodes labelled "democratic peace," "liberal trade and peace," "gender," and "human security," which are all purple clusters that include roughly even numbers of "peace" and "conflict" articles. ${ }^{11}$ Indeed, an investigation of the exact patterns of citation within these heterogeneous clusters (see the replication spreadsheet cited in the Appendix) indicates that there is substantial exchange between the "peace"- and "conflict"-focused articles that constitute these four clusters. Most notably, 38 percent of within-cluster citations for "democratic peace" link from studies coded as "peace" to studies coded as "conflict" and vice versa. This is also the case for 38 percent of within-cluster citations for "liberal trade and peace."

Cross-cluster exchange takes place when articles on different topics cite one another, and that citation crosses the peace/conflict divide. In Figure 3, such an exchange is most likely to occur where there are links between clusters of different colors (i.e. different "peace-conflict orientations") and, hence, those clusters are positioned near one another. This is the case for "democratic peace," "liberal trade and peace," and "gender," all of which are "mixed" (purple) clusters that are embedded within a dense web of "conflict"-oriented (red) clusters. By looking in detail at the nature of the incoming and outgoing links for these three clusters (again, see the relevant spreadsheet referenced in the Appendix), it becomes clear that the "democratic peace" and "liberal trade and peace" -- in particular -- play host to a number of "peace" articles that are cited by, and/or cite, "conflict" articles in neighboring clusters. These "mixed" clusters also include a limited number of "conflict" articles that are cited by, and/or cite, "peace" articles that are housed in other clusters. These inward and outward connections across the peace/conflict divide mean that studies of the "democratic peace" and "liberal trade and peace" can be seen to act as intellectual hubs, which connect to studies of "peace" on various topics and also to various studies of "conflict."

Ultimately, therefore, "democratic peace" and "liberal trade and peace" stand out as the two topics that build some bridges within an otherwise largely divided field, as represented by our sample. Not only do discussions of these topics often breach the peace/conflict divide but, when articles on these topics connect to works on other topics, those connections sometimes cross the putative divide. The data we have do not offer clues as to why these two topics are

\footnotetext{
${ }^{11}$ These are the only four clusters with peace-conflict orientations in the range from -0.5 to +0.5 . The exact size of all clusters, and the distribution of "peace" and "conflict" articles in those clusters, is detailed in the Appendix.
} 
particularly good at creating bridges. However, one plausible explanation is that both of these topics relate to structural conflict prevention, and treatments of any kind of preventive measure will necessarily engage with studies of the outcome that is to be prevented (in this case, war) and with studies of the outcome that is ultimately observed (here, peace).

\section{Discussion: Understanding the Violence Bias}

While this study is primarily heuristic, rather than explanatory, it is worth reflecting on possible accounts of the trends we have identified, with a view to prompting debate and discussion, going forward. Thus, in this section, we offer institutional, methodological, sociological and geographic explanations of why there appears to be a violence bias in peace and conflict studies, which sets studies of "conflict" apart from studies of "peace." We build our claims on the back of findings from our manually-coded data, though our inferences are necessarily tentative because the data required to build comprehensive explanations of the observed trends is beyond the scope of this study.

From an institutional perspective, the privileged position of the study of violent "conflict" in the discipline may be a legacy of intellectual assumptions held by early peace and conflict scholars, who believed that war could only be stopped if its causes were systematically studied and understood. Starting from this assumption, some of the founding figures of the discipline -- particularly those in the United States -- established research institutes, databases, and journals that focused specifically on the causes of war. Scholars associated with those institutions then published materials and trained students who adopted and diffused the idea that peace research involves asking questions about violent conflict (see Buzan and Hansen 2009, chs. 5-6). Over time, that idea has been passed down through generations of peace and conflict scholars and, as such, it remains a cornerstone of the field today. Indeed, only a limited number of scholars who publish in mainstream journals openly reject the assumption that we need to explain the root causes of war in order to understand paths to peace. ${ }^{12}$ Consequently, many -- if not most -- contemporary peace researchers start their careers by focusing on the causes of collective violence. As their careers advance, those scholars then encounter incentives which reinforce that focus. State, intergovernmental, and private funding agencies, for example, offer sizable grants to support research on the causes of war and violence (Woodward 2007, 149), and the top journals primarily publish articles on those topics, as

\footnotetext{
${ }^{12}$ For a rare example of such a critique, see Woodward (2007).
} 
illustrated above. There are, therefore, institutional and individual inducements for scholars to study violent conflict, rather peace.

A second reason for the proclivity of scholars to study violence may lie in questions of method. Specifically, it is currently easier to empirically study war and violence, rather than peace, peacemaking, and peacebuilding. After all, violence can be observed. By contrast, peace is commonly understood as a non-outcome (i.e. the absence of violence; see Klein et al. 2008). When conceptualized thus, it is evidently difficult to study peace-related topics without first studying violence. Indeed, until recently, it was nearly impossible for quantitative scholars to investigate anything other than the causes of war because most of the major peace and conflict databases were essentially repositories of the Correlates of War and violence (Johansen 2006), rather than the correlates of peace. The impact of this data constraint on the substance of quantitative peace research is supported by the evidence we gathered on scholars' methods; in our manually-coded sample, authors who relied on quantitative methods primarily studied violent conflict (see Figure 4) -- presumably, in part, because that is where the data lie. By contrast, there was a more balanced substantive focus to qualitative studies. The figure also reports the substantive focus of articles that were primarily theoretical in nature, and those that used mixed methods.

Figure 4. Methods, differentiated by content (manually coded data)
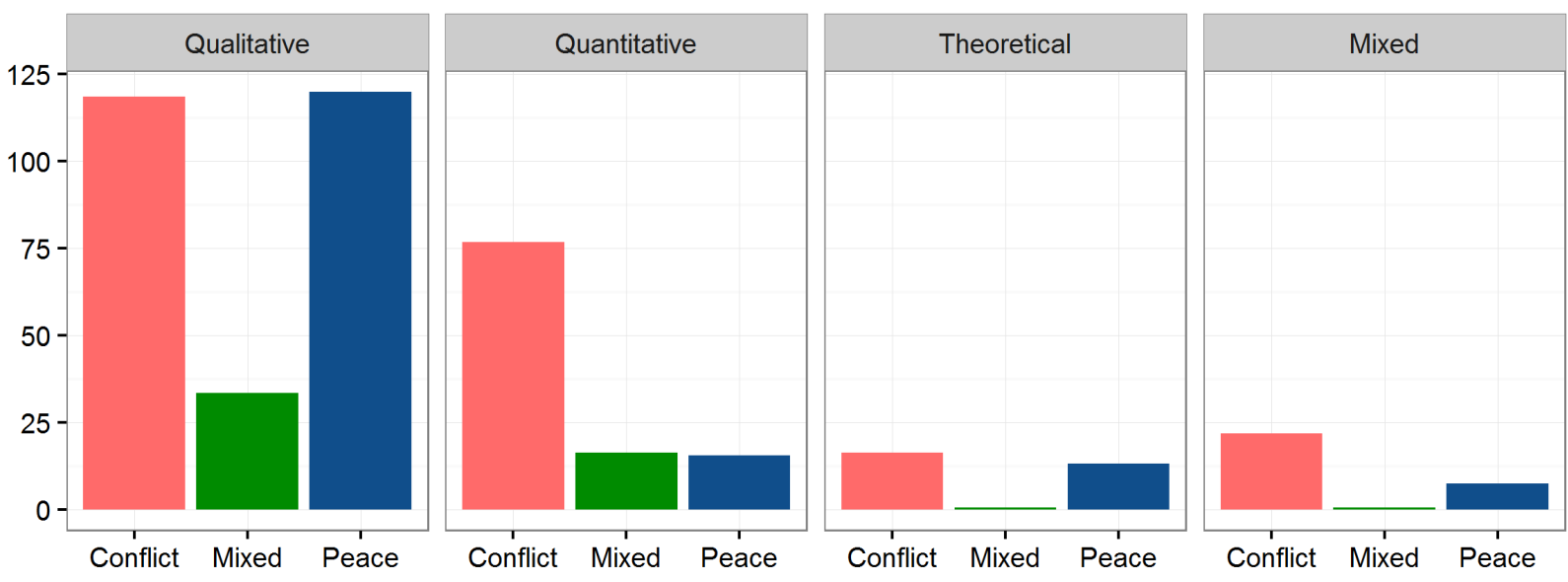

Our biographical data on authors provokes consideration of a further explanation of the dominance of "conflict" studies. Specifically, it appears that the discipline is highly gendered. In our sample, male authors were roughly twice as likely to study "conflict" as "peace," while female authors were slightly more likely to write on "peace" than "conflict" (see Figure 5). Thus, it appears that there is a strong violence bias among male scholars, but not among 
women. If there were roughly similar numbers of men and women writing in the field overall, then there would be a limited -- but not radical -- substantive imbalance in favor of studies of "conflict." However, this is not the case. Rather, the vast majority of articles in our sample were written by men and, given the tendency of men to study violence and war, there is an inclination in that direction across the sample as a whole. Thus, it seems that gender plays a role in shaping what we study in the field of peace and conflict, ${ }^{13}$ just as it is sometimes argued to play a role in shaping how we act in relation to the practice of peace and conflict (e.g. Enloe 2005; Hudson et al. 2009).

Figure 5. Author gender, differentiated by content (manually coded data)
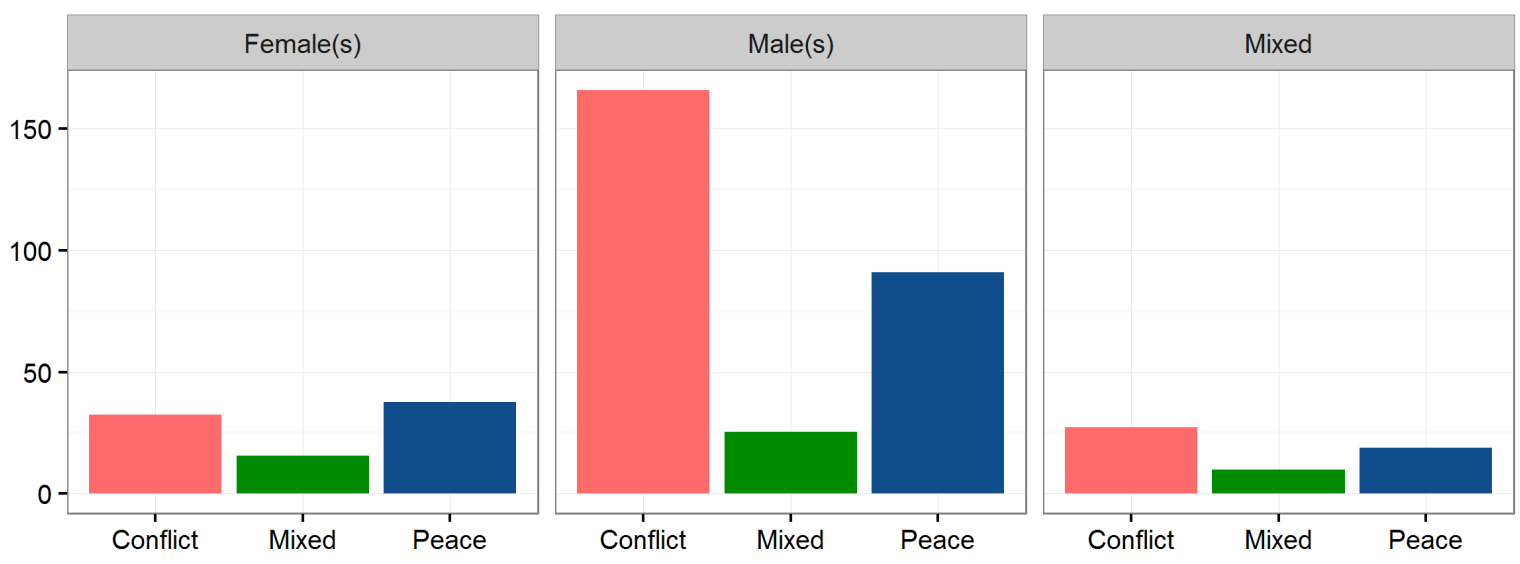

Finally, it is worth noting that our biographical data point to a clear distinction between work produced by scholars based at North American institutions, who write around three studies of "conflict" for every one study of "peace," and scholars based in Europe, who treat the two topics in roughly equal measure (see Figure 6). Perhaps this should not be surprising. After all, it has long been assumed that peace and conflict research in North America focuses on the study of war, while Europe-based scholars lean more toward the substantive investigation of peace. As of now, the reasons for that distinction have not been established, although one could speculate that institutional, epistemological, and even normative differences contribute to the trans-Atlantic divide. Given the high degree of mobility of the academic labor market, it is also likely that pre-existing proclivities to study one topic or

\footnotetext{
${ }^{13}$ Maliniak et al. (2013) suggest that men are more likely to cite their own work than women. Since peace and conflict studies is dominated by men, and men tend to write on "conflict," gender may play a role in ensuring that "conflict" articles receive more citations, on average, than "peace" articles.
} 
another are reinforced by academic migration patterns, so that scholars with an interest "conflict" move to North American institutions, while others may move themselves to Europe.

Figure 6. Author region, differentiated by content (manually coded data)
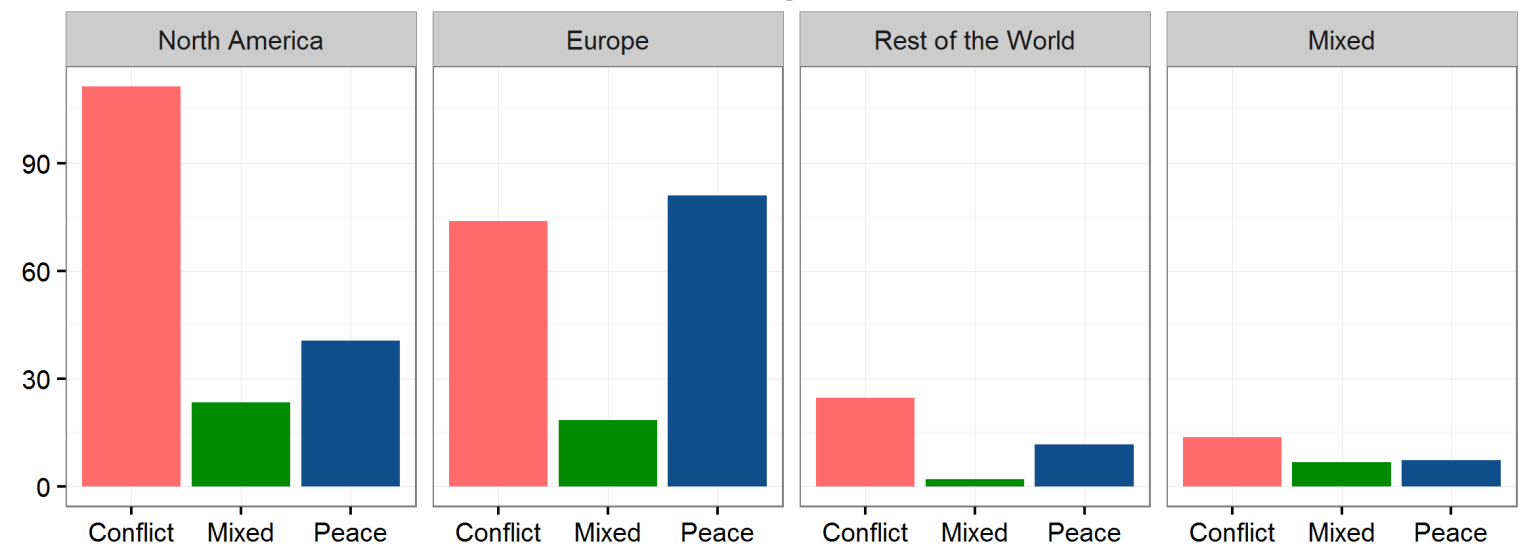

\section{Conclusion}

Trends in the state of the discipline are of interest in any academic field. In peace and conflict studies, however, such trends are not just of interest; they are also ontologically significant because the discipline was founded with the clear goal of understanding the dynamics of war in order to contribute to the peaceful management of conflict. Given that goal, a regular stock take of research in peace and conflict studies is needed, so that scholars in the field can know whether their works are contributing to a collective realization of that shared aim.

We have tried to perform such a stock take here, by addressing two questions. We first sought to identify what peace and conflict scholars study. Based on a large sample of articles from leading political science and international relations journals, we found that peace and conflict studies is dominated by works that investigate war and violence; such studies constitute a majority of classifiable articles in our sample, the top journals privilege such studies, and they are cited most frequently. That said, we also found that there is a substantial -- albeit smaller - body of literature that considers the prevention of, and responses to, violent conflict.

As a second step, we investigated whether there are connections between articles that focus on peace and those that explore conflict, in order to establish whether peace and conflict studies constitutes a coherent community, or a divided discipline. Here, we found qualified evidence of division. Studies of "conflict" tend to be highly insular, largely citing other studies of war and violence. Studies of "peace" tend to be less insular, although we still see more inter- 
citation among articles within that category than we would expect to see if there was complete integration and exchange between studies of "peace" and "conflict."

As an extension of our second question, we looked at whether particular topics facilitate bridging across the peace/conflict divide. Here, we found that two topics, in particular "democratic peace" and "liberal trade and peace" -- act as focal points for communication and exchange across the discipline because they can be studied either from a perspective of "peace" or a perspective of "conflict." We also found that studies of these topics are connected to studies of other topics in the field, and those connections sometimes transcend the peace/conflict divide.

From a purely empirical perspective, these findings are neither encouraging nor discouraging. They simply reflect what we do, and how we do it. From a normative perspective, however, our study suggests that peace and conflict studies may not be fulfilling its selfassigned objective of trying to understand the relationship between processes of violent conflict and processes of peace. Such an understanding can arguably only be developed if there is dialogue between studies of each of these topics and, at present, it appears that such dialogue is limited. That said, three recent developments offer possibilities for an increased degree of balance and communication across research areas in the discipline.

First, while studies of violence have dominated until now, new sources of data promise to open up scope for the study of conflict prevention and response. Specifically, datasets on nonviolent resistance (e.g. the NAVCO Data Project n.d.) and conflict management (e.g. UCDP Third Party Peacemaking Project n.d.) are making it possible for scholars to conduct "hard-nosed" research on pacific themes. Such research is a welcome addition to the large body of sophisticated studies of violent conflict that already exist.

Second, although there have previously been practical constraints (in the form of word limits) on the capacity of authors to publish articles that address violent conflict and conflict prevention or response in a single study, the digitization of publishing promises to remove those constraints. Specifically, online appendices offer authors of conflict studies an opportunity to discuss the implications of their research for peace and peacemaking, while authors of articles that focus on responses to violent conflict could use such appendices to build their studies of peace on top of rigorous understandings of conflict dynamics.

Finally, prominent political science blogs, such as Political Violence @ a Glance, The Duck of Minerva, and The Monkey Cage increasingly offer authors opportunities to expand their contributions beyond constraints that are imposed by traditional publishing paths. Not only do these blogs invite researchers to reflect on the policy implications of their work, but 
they offer scholars an opportunity to reach an audience beyond the academy -- where decisions about peace and conflict are ultimately taken. 


\section{Acknowledgements}

The authors contributed equally to the production of this article. Jonathan Bright's contribution was partially supported by the VOX-Pol project, financed by the EU's 7th Framework Programme (Grant 312827). We thank Sara Usher and Dana Landau for their invaluable research and coding assistance. We also thank Ariel Ahram, Erica Chenoweth, Daniel Maliniak, Jonathan Monten, Oisín Tansey, Peter Wallensteen, and participants at the 2016 annual conferences of OxPeace and the International Studies Association for comments on earlier drafts of this article. All views, along with any errors, omissions, or misrepresentations are, of course, our own. 


\section{References}

Berdal, Mats. 2010. "The Security Council and Peacekeeping." In The United Nations Security Council and War: The Evolution of Thought and Practice Since 1945, edited by Vaughan Lowe, Adam Roberts, Jennifer Welsh, and Dominik Zaum, 175-204. Oxford: Oxford University Press.

Boulding, Kenneth E. 1978. Stable Peace. Austin: University of Texas Press.

Buzan, Barry, and Lene Hansen. 2009. The Evolution of International Security Studies. Cambridge: Cambridge University Press.

Chen, Chaomei. 1999. "Visualising Semantic Spaces and Author Co-citation Networks in Digital Libraries.” Information Processing \& Management 35 (3): 401-20.

Clemens, Julie L. 2012. "Peace and Conflict Studies versus Peace Science.” In The Encyclopedia of Peace Psychology, edited by Daniel J. Christie, 767-71. Chichester: WileyBlackwell.

Deutsch, Karl W. 1970. "Quincy Wright's Contribution to the Study of War: A Preface to the Second Edition.” Journal of Conflict Resolution 14 (4): 473-78.

Enloe, Cynthia. 2005. "What if Patriarchy Is 'the Big Picture'? An Afterword." In Gender, Conflict, and Peacekeeping, edited by Dyan Mazurana, Angela Raven-Roberts, and Jane Parpart, 280-83. Lanham, MD.: Rowman \& Littlefield.

Fearon, James D. and David D. Laitin. 2003. "Ethnicity, Insurgency, and Civil War." American Political Science Review 97 (1): 75-90.

Fortunato, Santo. 2010. “Community Detection in Graphs.” Physics Reports 486 (3-5): 75174.

Fruchterman, Thomas M.J. and Edward M. Reingold. 1991. "Graph Drawing by ForceDirected Placement." Software: Practice and Experience 21 (11): 1129-64.

Galtung, Johan. 1964. “An Editorial.” Journal of Peace Research 1 (1): 1-4.

-----. 1969. “Violence, Peace, and Peace Research.” Journal of Peace Research 6 (3): 16791.

1985. "Twenty-Five Years of Peace Research: Ten Challenges and Some Responses." Journal of Peace Research 22 (2): 141-58.

1996. Peace by Peaceful Means : Peace and Conflict, Development, and Civilization. London: Sage Publications.

Gleditsch, Nils Petter, Jonas Nordkvelle, and Håvard Strand. 2014. "Peace Research - Just the Study of War?” Journal of Peace Research 51 (2): 145-58.

Grimmer, Justin, and Brandon M. Stewart. 2013. "Text as Data: The Promise and Pitfalls of Automatic Content Analysis Methods for Political Texts." Political Analysis 21 (3): 267-97. 
Hudson, Valerie M., Mary Caprioli, Bonnie Ballif-Spanvill, Rose McDermott, and Chad F. Emmett. 2008/9. "The Heart of the Matter: The Security of Women and the Security of States." International Security 33 (3): 7-45.

Human Dignity and Humiliation Studies. n.d. List of Peace and Conflict Resolution Journals. Accessed September 3, 2015. Url: http://www.humiliationstudies.org/newsold/archives/001060.html

IPRA. n.d. Directory Guide of Peace Research. Accessed September 3, 2015. Url: http://ipra.terracuranda.org/index.html

Johansen, Jørgen. 2006. "Peace Research Needs to Re-Orient." In Peace Studies in the Chinese Century: International Perspectives, edited by Alan Hunter, 31-38. Aldershot: Ashgate Publishing.

Keen, David. 2000. "War and Peace: What's the Difference?" International Peacekeeping 7 (4):1-22.

Kelman, Herbert. 1981. "Reflections on the History and Status of Peace Research." Conflict Management and Peace Science 5 (2): 95-110.

------. 2012. "Social Psychology and the Study of Peace: Personal Reflections." In The Oxford Handbook of Intergroup Conflict, edited by Linda Tropp, 361-72. Oxford: Oxford University Press.

Klein, James P., Gary Goertz, and Paul Diehl. 2008. "The Peace Scale: Conceptualizing and Operationalizing Non-Rivalry and Peace.” Conflict Management and Peace Science 25 (1): $67-80$.

Kristensen, Peter M. 2012. "Dividing Discipline: Structures of Communication in International Relations.” International Studies Review 14 (1): 32-50.

Lehmann, Sune, Lautrup, Benny, and Jackson, Andrew D. 2003. "Citation Networks in High Energy Physics." Physical Review E 68: 026113.

Lopez, George A. 1985. "A University Peace Studies Curriculum for the 1990s.” Journal of Peace Research 22 (2): 117-28.

MacGinty, Roger. 2010. "No War, No Peace: Why So Many Peace Processes Fail to Deliver Peace." International Politics 47 (2): 145-62.

Maliniak, Daniel, Susan Peterson, and Michael J. Tierney. 2012. TRIP Around the World: Teaching, Research, and Policy Views of International Relations Faculty in 20 Countries. Williamsburg, VA: The Institute for the Theory and Practice of International Relations, College of William and Mary.

Maliniak, Daniel, Ryan Powers, and Barbara F. Walter. 2013. "The Gender Citation Gap in International Relations." International Organization 67 (4): 889-922.

NAVCO Data Project. n.d. University of Denver. Accessed September 9, 2015. Url: https://www.du.edu/korbel/sie/research/chenow_navco_data.html 
Paris, Roland. 2011. "Ordering the World: Academic Research and Policymaking on Fragile States." International Studies Review 13 (1): 58-71.

Peace and Collaborative Development Network. n.d. Guide to MA Program[s] in Peace and Conflict Resolution and Related Fields. Accessed September 3, 2015. Url:

https://pcdnetwork.org/resources/guide-to-ma-program-in-peace-and-conflict-resolution-andrelated-fields/

Rapoport, Anatol. 1975. Approaches to Peace Research. In War, Its Causes and Correlates, edited by Martin A. Nettleship, R. Dalegivens, and Anderson Nettleship, 43-53. The Hague and Chicago: Mouton, and Aldine Publishing.

Rosvall, Martin, and Carl T. Bergstrom. 2008. "Maps of Random Walks on Complex Networks Reveal Community Structure.” PNAS 105 (4): 1118-23.

Russett, Bruce M., and Marguerite Kramer. 1973. "New Editors for an 'Old' Journal." Journal of Conflict Resolution 17 (1): 3-6.

Shibata, Naoki, Yuya Kajikawa, Yoshiyuki Takeda, and Katsumori Matsushima. 2008. "Detecting Emerging Research Fronts Based on Topological Measures in Citation Networks of Scientific Publications.” Technovation 28 (11): 758-75.

Sillanpää, Antti, and Tommi Koivula. 2010. "Mapping Conflict Research: A Bibliometric Study of Contemporary Scientific Discourses." International Studies Perspectives 11 (2): $148-71$.

TRIP. 2013. Codebook and User's Guide for TRIP Journal Article Database. Accessed February 24, 2016. Url: https://grads.polisci.wisc.edu/rpowers/files/trip_codebook_2013.pdf

UCDP Third Party Peacemaking Project. n.d. Uppsala University, Sweden. Accessed May 10, 2017. Url:

http://www.pcr.uu.se/research/ucdp/program_overview/current_projects/third+_party_peace making+l

Vasquez, John A. 1976. "Toward a Unified Strategy for Peace Education: Resolving the Two Cultures Problem in the Classroom." Journal of Conflict Resolution 20 (4): 707-28.

Wallensteen, Peter. 2001. The Growing Peace Research Agenda. Kroc Institute Occasional Paper, No. 21. Notre Dame: Kroc Institute for International Peace Studies.

-----. 2002. Understanding Conflict Resolution: War, Peace, and the Global System. London: Sage Publications.

------. 2011. The Origins of Contemporary Peace Research. In Understanding Peace Research: Methods and Challenges, edited by Kristine Hoglund and Magnus Öberg, 14-32. Abingdon: Routledge.

Walt, Stephen M. 1991. “The Renaissance of Security Studies.” International Studies Quarterly 35 (2): 211-39. 
Woodward, Susan L. 2007. "Do the Root Causes of Civil War Matter? On Using Knowledge to Improve Peacebuilding Interventions." Journal of Intervention and Statebuilding 1 (2): $143-70$. 


\section{APPendiX To ‘A Divided Discipline? MaPping Peace ANd Conflict Studies'}

Jonathan Bright, Oxford Internet Institute, University of Oxford

John Gledhill, Department of International Development, University of Oxford

This appendix contains details of: our survey of scholars; our manual classification technique (including our codebook and inter-coder reliability scores); the automatic classification technique; the automatic detection and labelling of citation clusters; how citations were detected; and journal coverage.

\section{Scholar Survey and Selection of Specialist Journals to Sample}

As described in the main body of the paper, when selecting specialist peace and conflict studies journals to sample for our study, we relied on responses that we received to a targeted survey of scholars in the field. To ensure that respondents reflected a cross-section of subfields and approaches in the discipline, we sent personal invitations to individuals associated with institutions that nominally focus on: war/security studies; peace studies; peace and conflict studies. We took care to ensure that those institutions were based in Europe, North America, and the 'Rest of the World' (albeit to a lesser extent). We sent around 320 direct invitations, and received 98 valid responses. We attribute this high response rate to the fact that invitations were personalized and potential respondents were assured that participation would only take a matter of minutes. We also had an open invitation for participation from members of a professional society of peace and conflict studies. However, since we only received a very small number of responses through this alternate method of solicitation, we chose to only use responses received through direct invitations.

Those who participated were first asked to self-identify as scholars of: (1) The causes and dynamics of conflict, violence, and/or war; (2) Responses to conflict, and/or postreconstruction; (3) Both of the above, in equal measure. As a second step, respondents were asked to nominate up to five influential journals in their area of study, and leading scholars in their area. We used their nominations of journals as a basis for choosing publications to sample for our study, although we excluded generic journals of international relations / political science from this selection because such journals were to be chosen using an alternate method, as described in the paper. We also excluded journals that do not appear in the SCOPUS database, since this was to be our source of citation data. With those restrictions in place, we then chose to sample the three journals that were top-ranked by scholars who self-identified as 
working on violent conflict and conflict responses 'in equal measure'. Those journals were the Journal of Peace Research (JPR), International Security (IS), and the Journal of Conflict Resolution (JCR). These journals also appeared at, or near, the top of the list of the most influential journals identified by scholars from each of the other two categories. We also chose to include three journals that were most-regularly identified by scholars from each of those other two categories, beyond $J P R, I S$, and $J C R$. Where there were ties in ranking, we used our own discretion to choose journals for inclusion, with diversity being the core criterion.

Results of the survey are presented below. Journals that were ultimately chosen from each category are marked in blue. Generic journals of international relations / political science, which were excluded from this selection of specialist journals, are marked in red.

\begin{tabular}{|c|c|}
\hline $\begin{array}{l}\text { Which of the following phrases best } \\
\text { describes the primary focus of your research } \\
\text { and writing? }\end{array}$ & $\begin{array}{l}\text { Most influential journals in your primary } \\
\text { area of research? }\end{array}$ \\
\hline $\begin{array}{l}\text { The causes and dynamics of conflict, } \\
\text { violence, and/or war. } \\
27 \text { responses, which is } \sim 28 \% \text { of total } \\
\text { responses }(27 / 98)\end{array}$ & $\begin{array}{l}\text { (For this response there were } 135 \text { total } \\
\text { nominations. } 9 \text { were invalid, resulting in a } \\
\text { total of } 126 \text { counted responses. The count } \\
\text { provided is the total number of times a } \\
\text { given journal was nominated.) } \\
\text { 1. International Security: } \mathbf{1 7} \\
\text { 2. Journal of Conflict Resolution: } \mathbf{1 5} \\
\text { 3. Journal of Peace Research: } \mathbf{1 4} \\
\text { 4. International Organization: } \mathbf{8} \\
\text { 5. International Studies Quarterly: } \mathbf{7} \\
\text { 6. American Political Science Review: } \mathbf{7} \\
\text { 7. Security Studies: } \mathbf{6} \\
\text { 8. Foreign Affairs: } \mathbf{5} \\
\text { 9. (=): Journal of Strategic Studies: } \mathbf{4} \\
\text { =Studies in Conflict and Terrorism: } \mathbf{4} \\
\text { =Terrorism and Political Violence: } \mathbf{4} \\
\text { 10. Others (Remainder) }\end{array}$ \\
\hline
\end{tabular}


Responses to conflict and/or post-conflict reconstruction.

27 responses, which is $\mathbf{2 8} \%$ of total responses $(27 / 98)$
(For this category there were 135 total nominations. 23 were invalid, resulting in a total of 112 counted responses. The count provided is the total number of times a given journal was nominated.)

1. Journal of Conflict Resolution: 9

2. Journal of Peace Research: $\mathbf{8}$

\section{International Peacekeeping: 6}

4. International Security: 5

5. Peacebuilding: 5 [Excluded, under five years, thus, insufficient data]

6. (=) International Organization: 4 Security Dialogue: $\mathbf{4}$ Third World Quarterly: 4

7. (=) Cooperation and Conflict: $\mathbf{3}$

=Global Governance: $\mathbf{3}$

=International Journal of Transitional Justice: $\mathbf{3}$

$=$ Journal of Peacebuilding and Development: $\mathbf{3}$

8. Others (Remainder)
Both of the above, in equal measure

32 responses, which is $\mathbf{2 3 2} \%$ of total responses (32/98)
(For this category there were 160 total nominations. 15 were invalid, resulting in a total of 145 counted responses. The count provided is the total number of times a given journal was nominated.)

1. Journal of Peace Research: 17

2. International Security: 14

3. Journal of Conflict Resolution: 11

4. International Studies Quarterly: 9

5. Security Studies: 5

6. (=) American Journal of Political 


\begin{tabular}{|c|c|}
\hline & $\begin{array}{l}\text { Science: } \mathbf{4} \\
\text { International Organization: } \mathbf{4} \\
\text { International Peacekeeping: } \mathbf{4} \\
\text { 7. (=) American Political Science Review: } \mathbf{3} \\
=\text { Journal of Strategic Studies: } \mathbf{3} \\
=\text { Peacebuilding: } \mathbf{3} \\
=\text { Studies in Conflict and Terrorism: } \mathbf{3} \\
=\text { Survival: } \mathbf{3} \\
=\text { Terrorism and Political Violence: } \mathbf{3} \\
=\text { Third World Quarterly: } \mathbf{3} \\
\text { 8. Others (Remainder) }\end{array}$ \\
\hline $\begin{array}{l}\text { None of the above. } \\
12 \text { responses, which is } \sim \mathbf{1 2} \% \text { of the total } \\
\text { responses }(12 / 98)\end{array}$ & N/A \\
\hline
\end{tabular}

\section{Manual Classification and Codebook}

The manual classification of articles was initially performed by two coders, who independently read through the title, abstract and full text of the 900 articles in our sample (50 from each journal of interest). The coders were asked to make four classification decisions: the substance of the article, the methods employed, the gender of the authors, and the region of origin of those authors. Other data were extracted from details provided in the SCOPUS database. The following codebook was used for the manual classification:

\begin{tabular}{|l|l|l|}
\hline Variable & Codes & Description \\
\hline Gender & Male(s) & All authors of the article are male \\
\hline & Female(s) & All authors of the article are female \\
\hline & Mixed & Authors of the article are a mix of males and females \\
\hline & Unknown & Impossible to establish the gender of the author(s) \\
\hline
\end{tabular}




\begin{tabular}{|c|c|c|}
\hline \multirow[t]{5}{*}{ Region } & North America & $\begin{array}{l}\text { All the authors of the article are based at North American } \\
\text { institutions (n.b. their nationality / country of birth is } \\
\text { irrelevant) }\end{array}$ \\
\hline & Europe & All the authors of the article are based at European institutions \\
\hline & $\begin{array}{l}\text { Rest of the } \\
\text { World }\end{array}$ & $\begin{array}{l}\text { All the authors of the article are based at institutions outside of } \\
\text { Europe or North America }\end{array}$ \\
\hline & Mixed & $\begin{array}{l}\text { Authors of the article are based at institutions from more than } \\
\text { one of the above three categories }\end{array}$ \\
\hline & Unknown & Impossible to establish the institutional location of the authors \\
\hline \multirow[t]{4}{*}{$\begin{array}{l}\text { Methods } \\
\text { employed } \\
\text { in the } \\
\text { article }\end{array}$} & Quantitative & $\begin{array}{l}\text { The question, analysis, and conclusion are primarily drawn } \\
\text { from one or more statistical studies, which are not } \\
\text { complemented by case studies. Alternatively, the article may } \\
\text { report descriptive data from a large-n study, or report newly } \\
\text { available large-n datasets and/or methods. }\end{array}$ \\
\hline & Qualitative & $\begin{array}{l}\text { The question, analysis, and conclusion are primarily drawn } \\
\text { from one or more cases, which are not complemented by } \\
\text { substantial statistical analysis. The article may include } \\
\text { specific, focused case studies and/or qualitative references to } \\
\text { a host of illustrative examples, drawn from diverse cases. } \\
\text { Alternatively, the article may report newly available } \\
\text { qualitative sources of data and/or methods. }\end{array}$ \\
\hline & $\begin{array}{l}\text { Mixed } \\
\text { methods }\end{array}$ & $\begin{array}{l}\text { The article includes at least one statistical analysis, and one or } \\
\text { more discernible case studies. Those case studies will } \\
\text { generally be marked off as a distinct section of the article. }\end{array}$ \\
\hline & $\begin{array}{l}\text { Normative / } \\
\text { theoretical / } \\
\text { conceptual }\end{array}$ & $\begin{array}{l}\text { The article deals primarily with theoretical or normative } \\
\text { concerns, which are explored conceptually, rather than } \\
\text { empirically. In this category, we also include studies that are } \\
\text { based on game-theory, but which do not include substantial } \\
\text { empirical work. (N.b. Where game theory is used as a basis for } \\
\text { generating hypotheses that are then empirically tested, the } \\
\text { article should be coded according to one of the first three } \\
\text { categories). Also include articles in this category that are } \\
\text { primarily aimed at clarifying concepts (e.g. 'What is peace?') }\end{array}$ \\
\hline
\end{tabular}




\begin{tabular}{|c|c|c|}
\hline & $\begin{array}{l}\text { None of the } \\
\text { above / } \\
\text { unknown }\end{array}$ & Impossible to establish the methods used \\
\hline \multirow[t]{2}{*}{$\begin{array}{l}\text { Substance } \\
\text { of the } \\
\text { article }\end{array}$} & $\begin{array}{l}\text { Conflict } \\
\text { Prevention } \\
\text { [This category } \\
\text { was later } \\
\text { combined with } \\
\text { 'Conflict } \\
\text { Responses' to } \\
\text { generate the } \\
\text { category } \\
\text { 'Peace'] }\end{array}$ & $\begin{array}{l}\text { Overall description: This category includes all articles that } \\
\text { investigate factors that can prevent conflictual relationships } \\
\text { from turning into active, violent conflict } \\
\text { The themes/topics that may fall within this category include: } \\
\text { - Specific studies of explicit 'conflict prevention' } \\
\text { efforts by diverse actors, including discussions of so- } \\
\text { called 'early warning' mechanisms, preventive } \\
\text { mediation, the application of economic sanctions in } \\
\text { lieu of violent interventions, and preventive military } \\
\text { interventions that explicitly take place before the } \\
\text { outbreak of collective violence. } \\
\text { - Studies of structural factors that may prevent } \\
\text { relations between diverse actors from turning violent, } \\
\text { such as the inter-democratic / liberal peace, or power } \\
\text { configurations at the international and/or domestic } \\
\text { levels that may serve to prevent the outbreak of } \\
\text { violence and/or war } \\
\text { Studies of strategic steps from international and/or } \\
\text { domestic actors, which are aimed at preserving peace, } \\
\text { such the formation of collective security } \\
\text { arrangements, arms control treaties, or neutrality } \\
\text { pacts } \\
\text { We explicitly exclude most discussions of the } \\
\text { 'Responsibility to Protect' (R2P) from this category } \\
\text { and, instead, code such studies under Category } 3 \\
\text { (Conflict responses). This is based on the recognition } \\
\text { that, although R2P lays claim to being a preventive } \\
\text { doctrine, (the limited number of) interventions that } \\
\text { have taken place under the auspices of R2P have } \\
\text { followed an outbreak of large-scale violence. Thus, in } \\
\text { practice, we understand R2P interventions to be } \\
\text { responses to conflict, which are aimed at preventing } \\
\text { an escalation of violence. }\end{array}$ \\
\hline & $\begin{array}{l}\text { Conflict } \\
\text { Processes and } \\
\text { Violence }\end{array}$ & $\begin{array}{l}\text { Overall description: This category includes all articles in } \\
\text { which the primary substantive focus of the study is the causes } \\
\text { and/or dynamics of conflict, violence, and war -- at the } \\
\text { international, domestic, and/or individual levels. Generally } \\
\text { (though not exclusively), such a focus is made manifest in the } \\
\text { ultimate outcome under investigation, which relates to one or }\end{array}$ \\
\hline
\end{tabular}




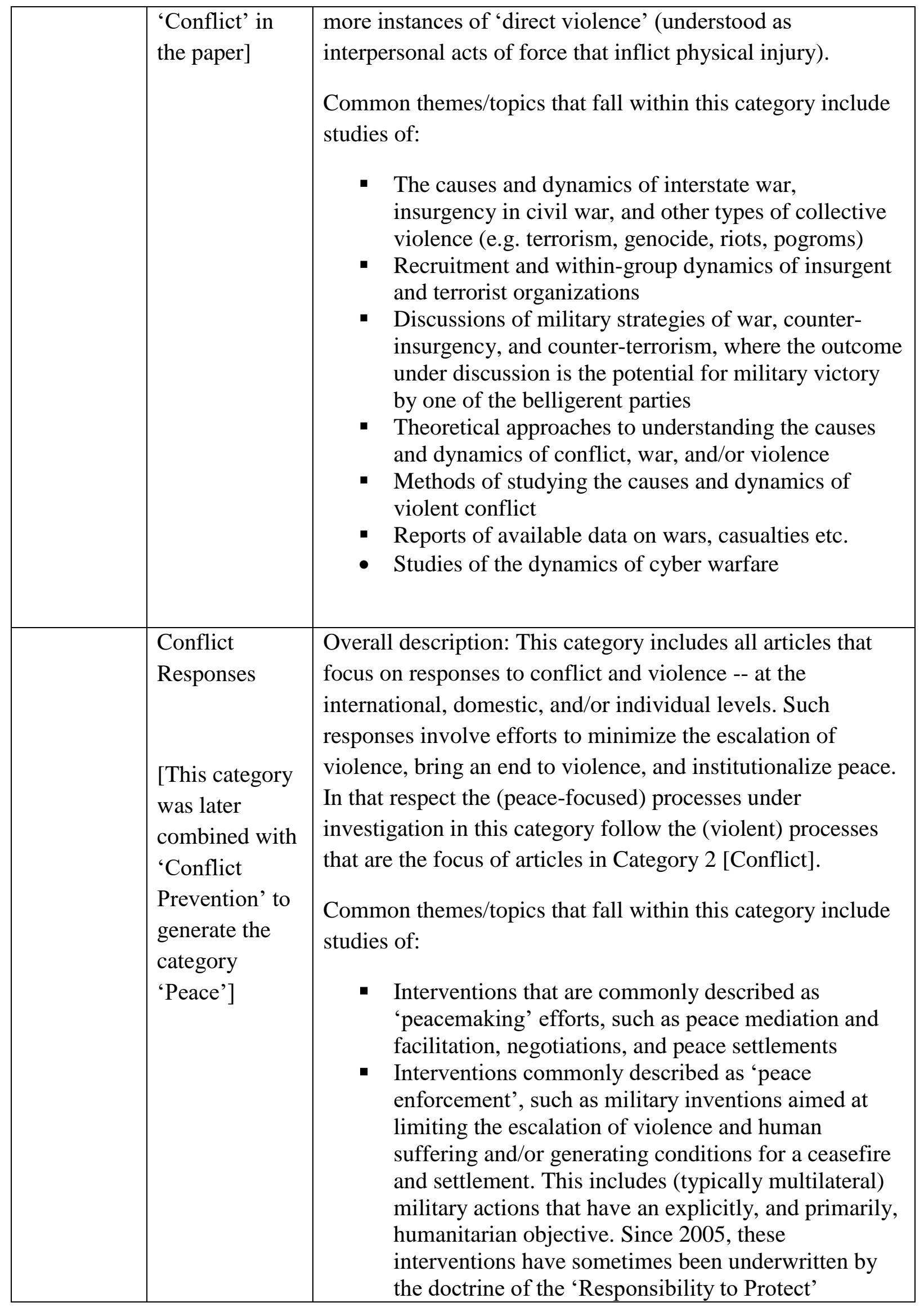




\begin{tabular}{|c|c|}
\hline & 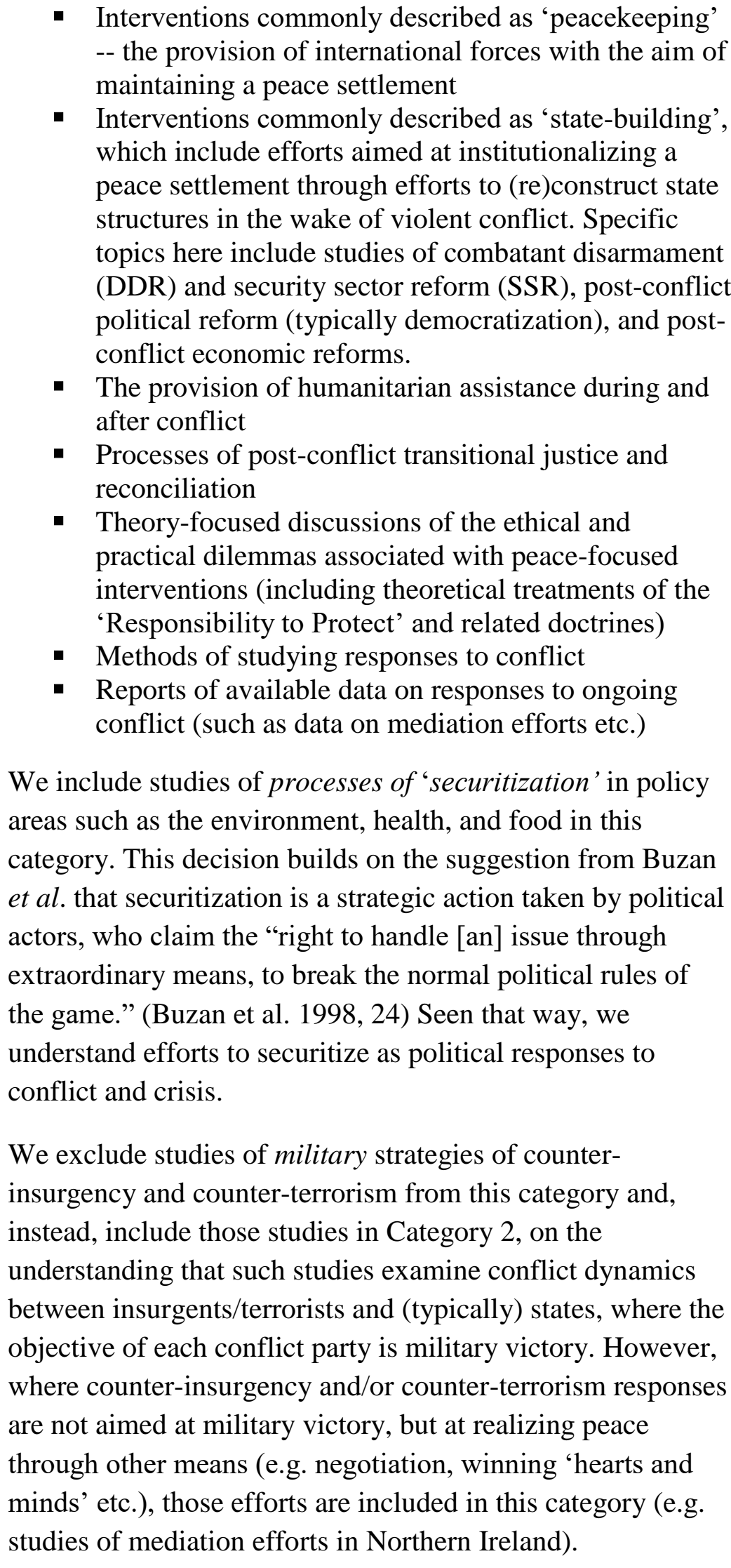 \\
\hline $\begin{array}{l}\text { Combined } \\
\text { Analyses }\end{array}$ & $\begin{array}{l}\text { Overall description: This category includes articles that } \\
\text { address two or more of the themes that are cited in Categories }\end{array}$ \\
\hline
\end{tabular}




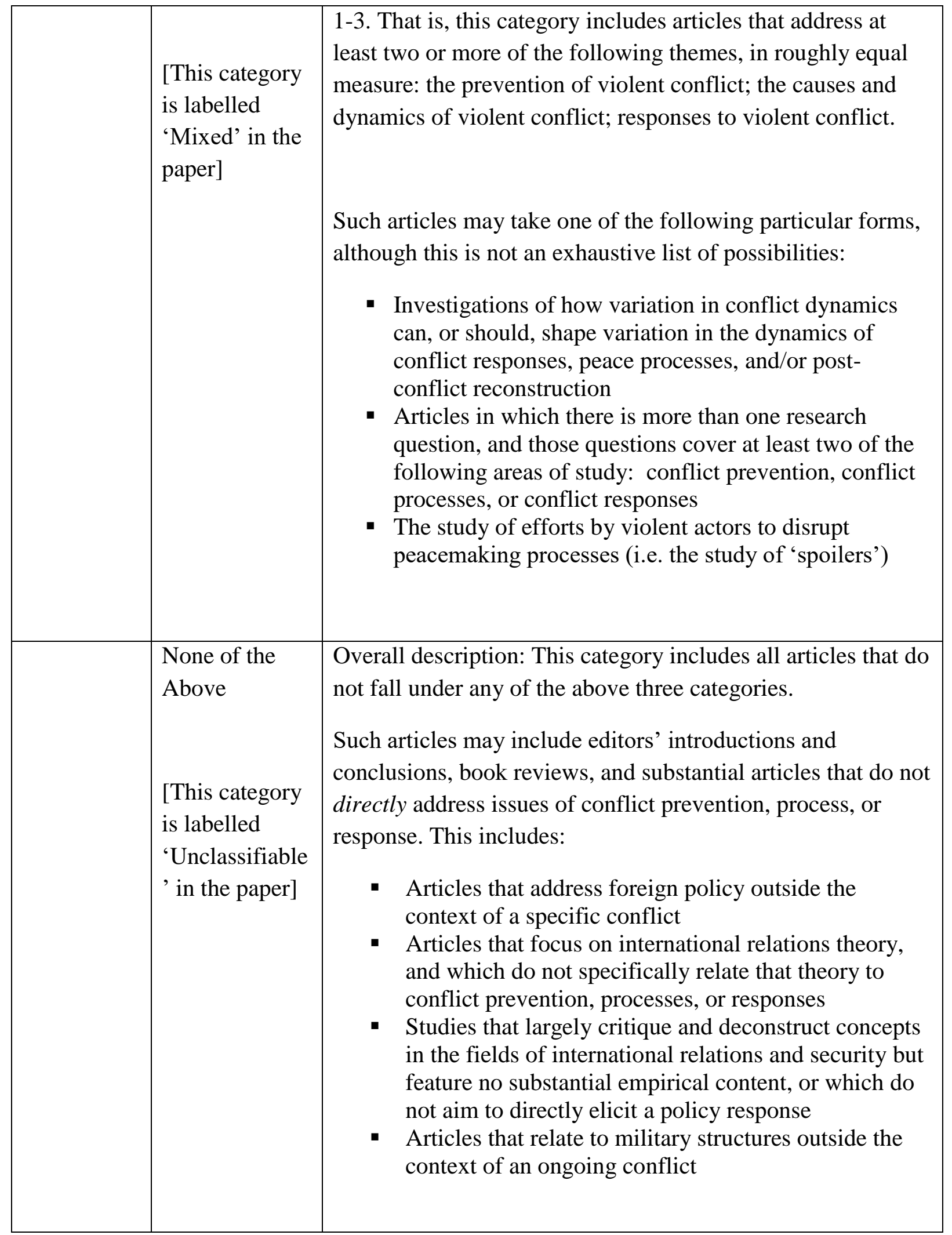

Note that, in the initial coding of 'Substance', we initially disaggregated the category of 'Peace' into two, more specific categories: Conflict Prevention, and Conflict Responses. 
That disaggregation was designed to give us maximum analytic flexibility. For the analysis, we ultimately re-aggregated the two categories into a single classification of 'Peace'.

The independent, double-coding of all articles meant we could calculate intercoder reliability scores. The following scores were observed for each category:

\begin{tabular}{|l|l|l|}
\hline Variable & $\begin{array}{l}\text { Percent } \\
\text { Agreement }\end{array}$ & $\begin{array}{l}\text { Krippendorff's } \\
\text { Alpha }\end{array}$ \\
\hline Gender & $93.3 \%$ & 0.90 \\
\hline Region & $92.1 \%$ & 0.89 \\
\hline Methods & $80.1 \%$ & 0.70 \\
\hline Substance & $74.4 \%$ & 0.60 \\
\hline
\end{tabular}

As highlighted in the main text, the variables 'Substance' and 'Methods' had lower than desired ICR scores. Hence, one of the authors then independently tripled-coded these variables where there was disagreement. Majority rule was then used to assign a final code to the article and, where there was continued disagreement, one of the authors took the decision on the final code.

\section{Automatic Classifier}

In this section, we describe our approach to constructing an automatic content classifier, which we used to automatically assign a 'Substance' code to articles in our dataset.

We created our classifier using the following steps. First, from our sample of 900 manually-coded articles, we removed all articles that had been coded as 'Mixed' for the 'Substance' category. These articles, we felt, would be too difficult to classify on a textual basis, as they inevitably contain themes and terms from both 'Peace' and 'Conflict' categories. We acknowledge this is a limitation, as it means that our automatic classifier could not recognise 'Mixed' articles. As a consequence, any 'Mixed' articles in the dataset will have been assigned to a category of either 'Peace', 'Conflict' or 'Unclassifiable'. We return to this point below.

Second, once we had removed the 'Mixed' articles, we separated the remaining articles into two groups. $75 \%$ of the articles were randomly selected for use as a 'training' group, while $25 \%$ were held back for use as a 'test' group. Making use of the training group, we first experimented with a wide range of different possible types of automatic classifier, before 
eventually choosing a 'Linear Support Vector Classifier'. This classifier works by representing each article as a point in high dimensional space, with each dimension being a "score" for a particular word within the title or abstract of the article (similar to our automatic labeller below, these scores are based on the frequency with which a word appears in a given title or abstract compared to its overall frequency in the corpus). The classifier attempts to draw lines through all the articles in such a way that the different categories are separated as clearly as possible. New articles can then be classified by determining their position in the same space, and observing which side of the line they fall on.

The accuracy of the classifier was evaluated in two stages. First, we made use of 10fold cross validation on our $75 \%$ training sample. This process splits the sample into 10 evenly sized chunks, and then tests the accuracy of the classifier on each of the chunks. This allowed us to compute average accuracy statistics for the classifier. This is more reliable than just taking one test sample, which could by chance either perform very well or very badly.

The results of this exercise are reported in the table below. Two major accuracy statistics were computed for each of our categories (and the total dataset): precision and recall. Precision refers to the number of 'true positives'. For example, the 'Conflict' category has $84 \%$ precision: this means, on average, in our 10 fold cross validation, $84 \%$ of the articles that were automatically labelled as 'Conflict' were also manually classified as 'Conflict'. Recall refers to the number of true positives as a percentage of the total possible number of true positives. For example, the 'Conflict' category has $72 \%$ recall, meaning that $72 \%$ of the articles that were manually classified as 'Conflict' were automatically labelled as 'Conflict'.

\begin{tabular}{|l|l|l|l|l|l|l|}
\hline Category & Precision & Recall & $\mathbf{N}$ & $\begin{array}{l}\% \text { Coded as } \\
\text { 'Conflict' }\end{array}$ & $\begin{array}{l}\% \text { as } \\
\text { Coded } \\
\text { 'Peace' }\end{array}$ & $\begin{array}{l}\text { \% Coded as } \\
\text { 'Unclassifiable' }\end{array}$ \\
\hline Conflict & $83 \%$ & $72 \%$ & 167 & & $1 \%$ & $27 \%$ \\
\hline Peace & $79 \%$ & $43 \%$ & 105 & $13 \%$ & & $44 \%$ \\
\hline Unclassifiable & $79 \%$ & $95 \%$ & 365 & $3 \%$ & $3 \%$ & \\
\hline Mixed & NA & NA & 49 & $32 \%$ & $34 \%$ & $34 \%$ \\
\hline Total & $80 \%$ & $80 \%$ & 637 & & & \\
\hline
\end{tabular}


The table shows that the main source of inaccuracy in the classifier is in the recall of 'Peace' articles: only $43 \%$ of the articles which were classified as 'Peace' in the manual sample were classified as such by the automatic classifier. However, the table also shows that the most of the 'misclassified' articles were coded, instead, as 'Unclassifiable' (44\% of 'Peace' articles were coded as 'Unclassifiable', while only $13 \%$ were coded as 'Conflict'). While this is a weakness, we do not consider it a serious problem for our purposes. Since our main aim when using the automatically classified data is to compare between 'Peace' and 'Conflict' categories, it is most important that the precision of categories is high, and that there is little intermingling between categories. This is the case here: only $1 \%$ of 'Conflict' articles were mistakenly classified as 'Peace', and only $13 \%$ of 'Peace' articles were mistakenly classified as 'Conflict'. This makes comparisons between the two categories reasonably valid.

These data also allowed us to look at the categories to which 'Mixed' articles are assigned by the automatic coder. We can see that, as might be expected, they are assigned almost evenly across our three categories of interest, with $34 \%$ going into the 'Unclassifiable' category, $32 \%$ into 'Conflict' and $32 \%$ into 'Peace'.

Finally, we made use of our $25 \%$ hold out sample, to assess the extent to which the classifier had been "overfitted" on our training data. This sample produced an accuracy of $75 \%$, which was within the range of values observed within the cross validation trial. Hence we are comfortable that overfitting was not a significant problem.

\section{Cluster Analysis and Naming}

In this section, we describe our approach to the detection and naming of the clusters of articles highlighted in the article, in Figure 3.

To detect clusters, we made use of the 'Infomap' community detection algorithm (Rosvall, Axelsson, and Bergstrom 2009). This algorithm, which was originally developed for, and tested on, academic citation patterns (Rosvall and Bergstrom 2008), is particularly useful for our purposes because it aims to capture communities on the basis of the way information flows around a network. It works by breaking apart the network into discrete clusters on the basis of hypothetical random flows of information around the network.

As we describe in the main document, after we had detected clusters, we then automatically detected names for those clusters. We did this by calculating 'tf-idf' scores for each of the words in titles of the articles in each cluster. These scores are the ratio of the 'term 
frequency' (i.e. the number times a given word appears within the titles in a cluster) to the 'inverse document frequency' (i.e. the number of times the word appears within the whole corpus of articles in our sample). Since words that appear frequently within a given cluster but infrequently outside it take high values, we took the five top-scoring words for each cluster and used them as a basis for devising 'readable' labels for the largest communities we detected. We calculated these scores for the ten biggest 'Peace', and ten biggest 'Conflict' clusters, on the basis of the absolute number of automatically-classified articles within each cluster. This gave rise to a total of 19 cluster names, because the Civil War and Rebellion cluster appeared in the top list for both 'Peace' and 'Conflict' articles. Hence we also chose to add two more clusters, to give us 10 distinct clusters in each group, resulting in a final list of 21 clusters.

The table below lists the composition of each of the named communities, the automatically extracted words, and the human readable name we devised on the basis of these words.

\begin{tabular}{|l|l|l|l|l|l|}
\hline $\begin{array}{l}\text { Total } \\
\text { Number of } \\
\begin{array}{l}\text { Articles in } \\
\text { Cluster }\end{array}\end{array}$ & $\begin{array}{r}\text { 'Peace' } \\
\text { Articles }\end{array}$ & $\begin{array}{l}\text { 'Conflict' } \\
\text { Articles } \\
172\end{array}$ & $\begin{array}{l}\text { Peace-Conflict } \\
\text { Orientation }\end{array}$ & $\begin{array}{l}\text { Top 5 terms, } \\
\text { Ranked by TF- } \\
\text { IDF score }\end{array}$ & $\begin{array}{l}\text { Readable } \\
\text { Label }\end{array}$ \\
\hline 34 & 23 & 158 & 0.84 & $\begin{array}{l}\text { civil; war; } \\
\text { conflict; rebel; } \\
\text { ethnic }\end{array}$ & Civil War and Rebellion \\
\hline 28 & 15 & 13 & -0.35 & $\begin{array}{l}\text { democrat; peac; } \\
\text { democraci; } \\
\text { interv; market }\end{array}$ & Democratic Peace \\
\hline 27 & 0 & 27 & -0.07 & $\begin{array}{l}\text { peac; liber; } \\
\text { trade; militar; } \\
\text { conflict }\end{array}$ & Liberal Trade and Peace \\
\hline & & 1.00 & $\begin{array}{l}\text { terrorist; terror; } \\
\text { transnat; } \\
\text { network; } \\
\text { timeseri }\end{array}$ & Transnational Terrorism \\
\hline
\end{tabular}

\footnotetext{
${ }^{14}$ Note that the terms in this column are word 'stems', which means that each word has been brought to its root to try and eliminate duplication. For example, 'peace' and 'peaceful' both have a stem of 'peac'.
} 


\begin{tabular}{|c|c|c|c|c|c|}
\hline 35 & 4 & 31 & 0.77 & $\begin{array}{l}\text { climat; conflict; } \\
\text { chang; weather; } \\
\text { environ }\end{array}$ & $\begin{array}{l}\text { Climate Change and } \\
\text { Conflict }\end{array}$ \\
\hline 25 & 1 & 24 & 0.92 & $\begin{array}{l}\text { violenc; civil; } \\
\text { civilian; war; } \\
\text { insurg }\end{array}$ & Civil War and Civilians \\
\hline 27 & 0 & 27 & 1.00 & $\begin{array}{l}\text { terror; } \\
\text { democraci; } \\
\text { terrorist; regim; } \\
\text { world }\end{array}$ & $\begin{array}{l}\text { Terrorism and Regime } \\
\text { Type }\end{array}$ \\
\hline 23 & 3 & 20 & 0.74 & $\begin{array}{l}\text { innov; british; } \\
\text { militari; } \\
\text { afghanistan; } \\
\text { transform }\end{array}$ & Military Innovation \\
\hline 23 & 5 & 18 & 0.57 & $\begin{array}{l}\text { clash; intern; } \\
\text { conflict; } \\
\text { network; civiliz }\end{array}$ & Civilization and Conflict \\
\hline 25 & 1 & 24 & 0.92 & $\begin{array}{l}\text { diversionari; } \\
\text { forc; militari; } \\
\text { use; intern }\end{array}$ & Diversionary War \\
\hline 26 & 7 & 19 & 0.46 & $\begin{array}{l}\text { gender; interst; } \\
\text { conflict; peac; } \\
\text { militar }\end{array}$ & Gender \\
\hline 20 & 2 & 18 & 0.80 & $\begin{array}{l}\text { militari; war; } \\
\text { vietnam; armi; } \\
\text { democraci }\end{array}$ & Militaries and Armies \\
\hline 15 & 12 & 3 & -0.60 & $\begin{array}{l}\text { reintegr; } \\
\text { demobil; } \\
\text { postconflict; } \\
\text { societi; } \\
\text { peacebuild }\end{array}$ & \begin{tabular}{|l|} 
Demobilization and \\
Reintegration
\end{tabular} \\
\hline 21 & 12 & 9 & -0.14 & $\begin{array}{l}\text { human; secur; } \\
\text { gender; vulner; } \\
\text { girl }\end{array}$ & Human Security \\
\hline
\end{tabular}




\begin{tabular}{|c|c|c|c|c|c|}
\hline 15 & 13 & 2 & -0.73 & $\begin{array}{l}\text { protect; respon; } \\
\text { darfur; china; } \\
\text { secur }\end{array}$ & $\begin{array}{l}\text { Responsibility to } \\
\text { Protect }\end{array}$ \\
\hline 21 & 2 & 19 & 0.81 & $\begin{array}{l}\text { religion; religi; } \\
\text { conflict; crusad; } \\
\text { faith }\end{array}$ & Religion and Conflict \\
\hline 14 & 12 & 2 & -0.71 & $\begin{array}{l}\text { peacekeep; } \\
\text { hypocrisi; exit; } \\
\text { peac; nation }\end{array}$ & Peacekeeping \\
\hline 13 & 10 & 3 & -0.54 & $\begin{array}{l}\text { prevent; } \\
\text { conflict; plan; } \\
\text { diplomaci; middl }\end{array}$ & Conflict Prevention \\
\hline 10 & 9 & 1 & -0.80 & $\begin{array}{l}\text { protect; libya; } \\
\text { côte; divoir; } \\
\text { peacekeep }\end{array}$ & R2P and Peacekeeping \\
\hline 13 & 11 & 2 & -0.69 & $\begin{array}{l}\text { hybrid; peac; } \\
\text { bottomup; } \\
\text { cypru; } \\
\text { peacebuild }\end{array}$ & Hybrid Peacebuilding \\
\hline 9 & 9 & 0 & -1.00 & $\begin{array}{l}\text { peacekeep; } \\
\text { cultur; oper; } \\
\text { peac; resolut }\end{array}$ & $\begin{array}{l}\text { Peacekeeping and } \\
\text { Conflict Resolution }\end{array}$ \\
\hline
\end{tabular}

\section{Citation Detection Algorithm}

In this section, we describe how our citation matching algorithm works. For each article in the data that we downloaded from SCOPUS, we had a list of all citations in that article. However, this information is presented as plain text. Hence, we used a computer script to scan the plain text of these references to see whether it contained the name of any other article in our dataset.

This script made a number of necessary simplifications. First, it ignored any titles that were less than three words long. These small titles most often appeared in the kinds of organisational pieces that are published in many journals (e.g. "editorial" or "front matter") and, hence, they cannot be used to refer to a unique article. Second, our script ignored articles appearing in the journal Foreign Affairs. These articles again had short titles, which are often 
quite ambiguous (e.g. Robert Madsen's 2009 article 'Comparing Crises'). Such works could easily be confused with, or found in, the titles of other articles - and so they were excluded.

We validated the script by asking one of the authors to manually check the citations matched to 90 of the articles that we investigated (i.e. $10 \%$ of the sample of manually-coded articles). 9 of these articles were found to have associated errors. The most common type of error (8/9) was that other articles citing this article had not been picked up by the citation matching script, seemingly because of slight spelling mistakes or changes in spelling. One of the articles was found to share its name with another article that was not in our sample, hence a citation had been recorded to an article that should not have been included in the study, given the parameters we set. While it is likely that this particular issue recurred a number of times throughout the dataset, broadly speaking, the citation matching algorithm appeared to be accurate and working well.

\section{Journal Coverage}

The table below describes the scope of data available on SCOPUS for all of our journals of interest. When reporting the results of our manual sample, the data for journals where some data was missing were scaled up to account for absences.

\begin{tabular}{|l|l|l|}
\hline Journal & $\begin{array}{l}\text { Number of } \\
\text { Articles in } \\
\text { Database }\end{array}$ & $\begin{array}{l}\text { Years of Data (20 is } \\
\text { the maximum) }\end{array}$ \\
\hline International Studies Quarterly & 735 & 20 \\
\hline Journal of Peace Research & 725 & 20 \\
\hline Journal of Conflict Resolution & 657 & 20 \\
\hline International Affairs & 648 & 20 \\
\hline Security Dialogue & 554 & 20 \\
\hline International Peacekeeping & 193 & 7 \\
\hline Terrorism and Political Violence & 533 & 20 \\
\hline Journal of Strategic Studies & 531 & 20 \\
\hline
\end{tabular}




\begin{tabular}{|l|l|l|}
\hline Foreign Affairs & 311 & 13 \\
\hline Millennium & 128 & 6 \\
\hline International Relations & 251 & 12 \\
\hline $\begin{array}{l}\text { European Journal of International } \\
\text { Relations }\end{array}$ & 366 & 19 \\
\hline Security Studies & 346 & 18 \\
\hline International Organization & 334 & 19 \\
\hline Cooperation and Conflict & 247 & 15 \\
\hline International Security & 295 & 18 \\
\hline World Politics & 304 & 19 \\
\hline Global Governance & 300 & 19 \\
\hline
\end{tabular}

\section{Spreadsheet Detailing Community Detection Links}

Alongside the replication data that we have posted online, which will be found at http://researchdata.ox.ac.uk, we have included an Excel spreadsheet that provides details of the data that underwrite the network analysis presented in Figure 3 of the main paper.

In the spreadsheet, the rows reflect data for clusters that serve as sources of citations, and the columns reflect data for clusters that serve as targets of citations. Thus, the intersections between the rows and columns reflect the nature of links between clusters. For each connection, data is provided on the 'Total' number of citation links between clusters, as well as the exact nature of those links. Links between two articles coded as 'Peace' appear in the 'P2P' column. Links from articles coded as 'Peace' to articles coded as 'Conflict' appear in the 'P2C' column. Links from articles coded as 'Conflict' to articles coded as 'Peace' appear in the 'C2P' column. And links between two articles coded as 'Conflict' appear in the 'C2C' column'.

To facilitate interpretation, an overview of external links between clusters can be viewed on the 'Summary' sheet of the spreadsheet. 


\section{Works Cited in Appendix}

Barry Buzan et al. 1998. Security: A New Framework for Analysis. Boulder, CO: Lynne Rienner.

Martin Rosvall et al. 2009. "The Map Equation.” European Journal of Physical Topics 178 (1): 13-23.

Martin Rosvall and Carl T. Bergstrom. 2008. "Maps of Random Walks on Complex

Networks Reveal Community Structure.” PNAS 105(4): 1118-23. 